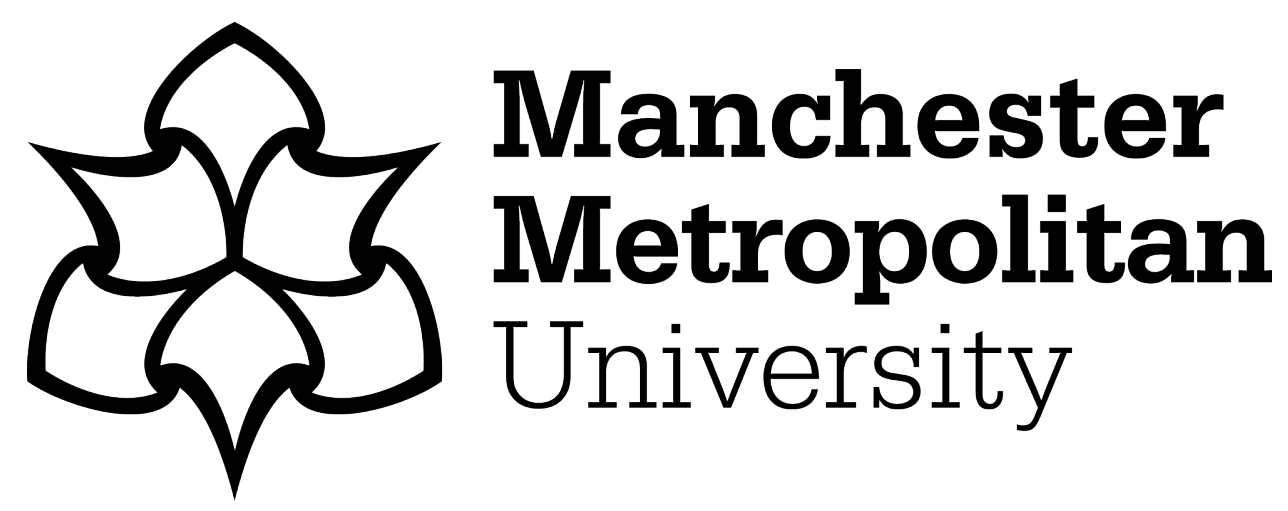

Rafique, H, Alroobaea, R, Munawar, BA, Krichen, M, Rubaiee, S and Bashir, AK (2020) Do digital students show an inclination toward continuous use of academic library applications? A case study. The Journal of Academic Librarianship, 47 (2). ISSN 0099-1333

Downloaded from: https://e-space.mmu.ac.uk/627623/

Version: Accepted Version

Publisher: Elsevier

DOI: https://doi.org/10.1016/j.acalib.2020.102298

Usage rights: Creative Commons: Attribution-Noncommercial-No Derivative Works 4.0

Please cite the published version 


\title{
Do Digital Students Show an Inclination Toward Continuous Use of Academic Library Applications? A Case Study
}

\author{
Hamaad Rafique ${ }^{\mathrm{a},{ }^{*}, \text { Roobaea Alroobaea }}{ }^{\mathrm{b}}$, Bilal Ahmed Munawar ${ }^{\mathrm{c}}$, Moez Krichen ${ }^{\mathrm{d}}$, \\ Saeed Rubaiee ${ }^{\mathrm{e}}$, Ali Kashif Bashir ${ }^{\mathrm{f}, \mathrm{g}}$
}

a School of Computer Science and Technology, University of Science and Technology of China, Hefei, Anhui and 230026, China hamaadrafique@mail.ustc.edu.cn

b Department of Computer Science, College of Computers and Information Technology, Taif University, P.O. Box 11099, Taif 21944, SaudiArabia r.robai@tu.edu.sa

cSchool of Computing and Information Technology, University of Wollongong, Northfields Ave Wollongong, NSW 2522, Australia bilalmunawar500@gmail.com

dFaculty of CSIT, Al-Baha University, Saudi Arabia \& ReDCAD Laboratory, University of Sfax, Tunisia moez.krichen@redcad.org eDepartment of Industrial and Systems Engineering, College of Engineering, University of Jeddah, Jeddah, Saudi Arabia salrubaiee@uj.edu.sa

fDepartment of Computing and Mathematics, Manchester Metropolitan University, Manchester M15 6BH, United Kingdom dr.alikashif.b@ieee.org

gSchool of Electrical Engineering and Computer Science, National University of Science and Technology (NUST), Islamabad, 24090,

Pakistan

\section{Corresponding author:}

\section{Hamaad Rafique*}

University of Science and Technology of China, China,

Jinzhai Road 96, Hefei, Anhui Province, Postal Code: 230026

Mobile phone: +86-13155120780

E-mail: hamaadrafique@mail.ustc.edu.cn, hamaadrafique@gmail.com 


\begin{abstract}
Rapid use of internet-based applications like mobile library applications (MLA) are depicting the modern era of digital students and literature broadly discussed the initial adoption of MLA among students. However, there is a need to investigate the continuance use intention of applications to overcome an acceptance-discontinuance phenomenon. Therefore, this research was performed for the empirical support toward continued usage of MLA by integrating an extended expectation confirmation model (EECM), technology acceptance model (TAM), media affinity theory, and service quality. This study worked on the focus of uncovering the factors which were creating hindrance in long term use of MLA. It was conducted with the self-controlled cross-sectional surveybased study. An overall 307 surveys were collected to verify the proposed theoretical model with structural equation modelling (SEM) technique. Finding of the study inferred that service quality, confirmation, MLA affinity, perceived usefulness, satisfaction and perceived ease of use are explaining the direct or indirect strong influence on continuous use of MLA. Current research empirically assessed to expose the deep intuition towards users' continuous usage intention of MLA. Outcomes will oblige as a controller for operative choices in development and resource distribution toward confirming the accomplishment of the mobile library application's mission and vision.
\end{abstract}

Keywords: Digital Library, Library Knowledge, Mobile library service, continuance usage intention, postadoption behaviour

\title{
1. Introduction
}

The drastic rise in wireless technologies especially mobile applications are transforming students into digital students, schools into digital schools and universities into digital universities. Digital students are defined as "students who use digital technologies more than the traditional one." Defined by (Gartner, 2015), the mandate for mobile apps development will raise five times quicker than interior information technology organizations' dimensions. As reported in the survey, $42 \%$ of organizations are expected to spend at an average of $31 \%$ on the development of mobile apps (Gartner, 2016). According to (Ju, Park, \& Kyoung, 2017), downloading of mobile applications reached $115 \%$ year-over-year-growth. Categorically explaining, downloading of productivity and utility apps grows to $150 \%$ and social apps up to $203 \%$ (Hsiao, Chang, \& Tang, 2016). Hence, we can predict that individuals are using mobile applications for a variety of diverse purposes like shopping, internet surfing, for tracking parcels, as route guides through google map, playing games, for social media sites, reading the newspaper and as well as for library services, etc., (Huh \& Kim, 2008)(Ali, Rafique, et al., 2019)(Omotayo \& Haliru, 2019).

Table 1: Types of a library with definitions

\begin{tabular}{llll}
\hline Sr.\# & Types of Library & Definitions & Source \\
\hline $\mathbf{1}$ & Online Library & $\begin{array}{l}\text { library resources (articles, books etc) retrieved through modest } \\
\text { search engines as a substitute of library sources. }\end{array}$ & (Joo \& Choi, 2016) \\
$\mathbf{2}$ & Digital Library & $\begin{array}{l}\text { library retrieved by handlers using web broadband and computer } \\
\text { by sitting at a demarcated location. }\end{array}$ & $\begin{array}{l}\text { (Zha, Zhang, \& } \\
\text { Yan, 2015) }\end{array}$ \\
$\mathbf{3}$ & $\begin{array}{l}\text { Mobile Library } \\
\text { Application }\end{array}$ & $\begin{array}{l}\text { application for library resources through wireless network } \\
\text { deprived of spatial and temporal limitations. }\end{array}$ & Yang, 2016) \\
& (MLA) & &
\end{tabular}


Digital library gave boast to knowledge and resources (Omotayo \& Haliru, 2019). Nowadays almost all research and educational material are available online. Therefore, digital students prefer to use digital, online or mobile libraries more frequently than the traditional library resources (Lee, Paik, \& Joo, 2012). Hence, to facilitate digital students, educational institutes are quickly adopting mobile applications like mobile library applications (MLA), to provide easy and fast contact to a diversity of digital resources, with rapid searching and browsing by overcoming temporal and spatial constraints (Omotayo \& Haliru, 2019). Literature has identified three major types of libraries that are defined in Table 1 above.

For better leverage of MLA benefits, public and private libraries must understand the behaviour of the users that cannot succeed without a deep understanding of how people or organisations are using emerging technologies such as MLA (Seethamraju, Diatha, \& Garg, 2018). For example, the current research was conducted at COMSATS University Islamabad Pakistan (CUI) which adopted MLA in spring 2014 with the name INSIGNIA ILS. However, its success depends on the initial acceptance by its intended user. This research is an extension of our previous work in which we measured the user's inspirations toward the initial acceptance of INSIGNIA ILS (Rafique, Omran, Shamim, Anwar, \& Bashir, 2020). However, in current work, we discussed the long-term practicability of a new information system (IS) that hinges on the continuous behaviour of the user than on primary adoption. However, a lot of this kind of techniques were applied in developed countries such as in China, South Korea, USA, Israel and Taiwan (Joo \& Choi, 2016)(Cheng, 2014)(Yoon, 2016). Despite this, we are unable to find an adaptation of these techniques in developing countries. A brief analysis of this adaptation is given in Table 2.

Therefore, one of the motivations of this research is a focus on the continuance usage instead of initial acceptance of MLA in academic libraries of Pakistan. Besides the investment of huge resources in education sectors within developing countries, users are still not using MLA in their study era. Hence, it is a need of an hour to keep intended users on MLA for a longer period, which is being developed with a massive investment of emerging country (Fu \& Inskip, 2019)(Yoon, 2016). As investment was done to facilitate users, so it is expected to be used continuously by the users for their aims and objectives. For this reason, the current research will report the following research interrogations (RQ1): Is EECM suitable for investigating the continuance use intention of MLA in academic libraries of Pakistan? (RQ2): How do the MLA drives of early acceptance decision effect the MLA continuance intention to practise in Pakistan?

To address the research queries, we proposed research model that is grounded on empirically authenticated existing theoretical models, i.e., the extended expectation confirmation model (EECM) (Bhattacherjee, 2001b), technology acceptance model (TAM) (Davis, 1989), along with service quality and MLA affinity theory (Perse, 1986). To clarify the extensive improvements in the clarification of the initial adoption and use behaviour of MLA, TAM is the most suitable model for this study. On the other hand, continuance usage intention is the major issue after the initial adoption of technology for long-term viability. Hence, for this purpose, EECM is the best-suited model for the current study. Besides that, consistency depends on the service quality and MLA affinity (perceived importance) of the applications, therefore, service quality and MLA affinity were integrated with the theoretical models. Thus, by integrating these two empirically validated models along with service quality and MLA affinity, we will try to explore the major factors of original adoption of a system, that will ultimately lead to continuance usage intention of MLA. Expected research outcomes will help the developers in realizing the important factors toward the continuance use of MLA, which will be considered while developing the application to overcome the fear of the use.

Our research contribution is twofold. At first, we integrated TAM (Davis, 1989) with EECM (Bhattacherjee, 2001b) for improving the understandability of continuance intention to use MLA along with service quality and MLA affinity. To the best of our knowledge, it's the first study that integrated TAM (Davis, 1989) and EECM (Bhattacherjee, 2001b) to identify the continuance usage of MLA with affinity theory (Perse, 1986) in developing nation context i.e., Pakistan. Secondly, investigation of an individuals' determinant toward continuance intention to use MLA will donate to the extensive body of scientific facts, that was not addressed so for in continuance usage intention toward MLA. It is very important to investigate this, because the majority of the researchers heavily focused on the investigation of initial adoption, however, this study hunts for the examination of a continuance usage intention of MLA which is very vital for long term practicability of IS 
(Bhattacherjee, 2001b).

Henceforth, the focus of current research is on the continuance usage of MLA, i.e., INSIGNIA ILS particularly focusing on the developing country. Pakistan government allocated a huge budget for ICT and continuously developing ICT infrastructure for its people. Hence, the users must be kept on board for a longer period, which ultimately helps us in updating the technology over time. In the current research, all the collected responses from the users will be analysed using statistical package for social science (SPSSv23) and analysis of moment structure (AMOSv23) tools. As it will help in receiving the closer look toward the factors which might be the expected barriers toward continuance usage.

Section two comprised of a brief explanation of both theoretical models integrated into this study along with service quality and MLA affinity. After that, the projected research model along with their statistical hypothesis is presented, followed by the proposed methodology. The article is concluded with the results which are followed by conclusion and limitations of the study.

Table 2: Research in a different context

\begin{tabular}{|c|c|c|c|c|c|c|}
\hline Study reference & Year & Context & Technology Type & $\begin{array}{l}\text { Initial } \\
\text { adoption }\end{array}$ & $\begin{array}{l}\text { Continuance } \\
\text { Usage }\end{array}$ & Model Used \\
\hline (Rafique et al., 2020) & 2020 & Pakistan & Mobile library application & $\checkmark$ & & TAM \\
\hline $\begin{array}{l}\text { (M. Zhang, Chen, \& } \\
\text { Chen, 2019) }\end{array}$ & 2019 & China & Mobile library application & $\checkmark$ & & TAM, ISST \\
\hline (F. Xu \& Du, 2019) & 2019 & China & Digital library & $\checkmark$ & & TAM, ISST \\
\hline (F. Xu \& Du, 2018) & 2018 & China & Digital library & $\checkmark$ & & TAM, ISST \\
\hline (Rafique et al., 2018) & 2018 & Pakistan & Mobile library application & $\checkmark$ & & TAM \\
\hline (Yoon, 2016) & 2016 & Korea & Mobile library application & $\checkmark$ & & TAM \\
\hline (Khan \& Qutab, 2016) & 2016 & Pakistan & HEC digital library & $\checkmark$ & & TAM \\
\hline (Joo \& Choi, 2016) & 2016 & USA & Online library resources & & $\checkmark$ & EECM \\
\hline $\begin{array}{l}\text { (Zhao, Deng, \& Zhou, } \\
\text { 2015) }\end{array}$ & 2015 & China & Mobile library application & & $\checkmark$ & ECM-ISC \\
\hline $\begin{array}{l}\text { (Alfaresi \& Hone, } \\
\text { 2015) }\end{array}$ & 2015 & UK & Mobile digital technology & $\checkmark$ & & TAM \\
\hline (Zha et al., 2016) & 2015 & China & $\begin{array}{l}\text { Digital library in a mobile } \\
\text { context }\end{array}$ & $\checkmark$ & & TAM \\
\hline $\begin{array}{l}\text { (Chen \& Chengalur- } \\
\text { Smith, 2015) }\end{array}$ & 2015 & USA & Library web portal & $\checkmark$ & & TAM \\
\hline (Aharony, 2014) & 2014 & Israel & Mobile libraries & $\checkmark$ & & TAM \\
\hline (Hu, Hu, \& Yan, 2014) & 2014 & China & Digital Library & $\checkmark$ & & TAM \\
\hline (Cheng, 2014) & 2014 & Taiwan & digital library & & $\checkmark$ & $\begin{array}{l}\text { ECM, TAM } \\
\text { and DMIS }\end{array}$ \\
\hline (Chang, 2013b) & 2013 & Taiwan & Mobile library application & $\checkmark$ & & TAM \\
\hline $\begin{array}{l}\text { (Al-faresi \& Patel, } \\
\text { 2012) }\end{array}$ & 2012 & UK & Mobile digital library & $\checkmark$ & & TAM \\
\hline (Hahn, 2012) & 2012 & USA & $\begin{array}{l}\text { Mobile augmented reality } \\
\text { app for library }\end{array}$ & $\checkmark$ & & TAM \\
\hline $\begin{array}{l}\text { (Park, Roman, Lee, \& } \\
\text { Chung, 2009) }\end{array}$ & 2009 & USA & Digital library system & $\checkmark$ & & TAM \\
\hline
\end{tabular}




\section{Theoretical Models}

\subsection{Extended Expectation Confirmation Model (EECM)}

Currently, post-adaptation of technology, i.e., MLA at an individual level is of main concern, and to study this behaviour, various researchers had adopted EECM in there research (Hsu \& Lin, 2015)(C. Xu, Peak, \& Prybutok, 2015)(Hsiao et al., 2016)(Albashrawi \& Motiwalla, 2019). (Bhattacherjee, 2001a) wished-for the extended expectation confirmation model (EECM) which is based on expectation confirmation theory (ECT) within marketing. He adopted information technology perspective of perceived usefulness from the technology acceptance model (TAM) (Davis, 1989). ECT claims that, post-purchase satisfaction of individual relay on perceived expectation and performance. The effect on the post-purchase can be measured either by positive or negative dissonance among expectation and performance (Oliver, 1980). By keeping this concept in mind, (Bhattacherjee, 2001a) projected EECM to envisage the continuance use of IS. This model is composed of three factors, which are used to explain and predict the continuance use of IT from an individual perspective i.e., confirmation of expectations, satisfaction and perceived usefulness as shown in Fig. 1. In EECM, satisfaction and perceived usefulness are considered as two chief variables in determining IS continuance intentions conferring to the initial expectations of consumers, which are having an impact on satisfaction. Together they forecast the continuance intention of IS toward MLA (i.e., INSIGNIA ILS in this study) in individual perspective.

In IT domain, particularly in the zone of mobile apps like e-shopping, m-learning or e-ticketing (Hsu \& Lin, 2015)(Albashrawi \& Motiwalla, 2019)(Hsiao et al., 2016)(C. Xu et al., 2015), various attempts have been made by adopting diverse models to go deeper into the belief of post-acceptance by focusing the individual perspective. However, insufficient research work was found on the continuance use of IS by concentrating individual viewpoint, therefore, by keeping the same theme, our research will address the post-acceptance of MLA, i.e., INSIGNIA ILS in Pakistan. The proposed model was developed to address the main objectives of our research that are based on the same theme, i.e. individual's behaviour after their initial adoption toward MLA.

Extension of EECM in our study is of vital importance, in which we will be able to understand the MLA post adaptation phenomena in a better way. We postulate that continuance intention to use MLA is dependent on the decision of a user when he/she is at the first stage of adopting MLA, which may ultimately inspire the user's elongated term viability.

\subsection{Technology Acceptance Model (TAM)}

This model has its foundation on the theory of reasoned action by (Fishbein \& Ajzen, 1977), and the theory of planned behaviour (Ajzen, 1991). According to the theory, the belief of the user determines their attitude toward things. An attitude is a factor which has the capability of controlling the behaviour of the user, that ultimately leads to behaviour intention. According to the basic TAM, its two core factors, i.e., perceived ease of use (PEOU) and perceived usefulness (PU) are the key features in explaining the user intent toward the use of technology (Davis, 1989). PEOU is defined as "using a specific system, he/she will be effort-free", whereas, PU is demarcated as "using a particular system he/she will be able to enhance his/her job performance" (Davis, 1989). These two determinants are easy to understand and must be considered by developers and requirement analysis engineer at developing and requirement gathering stage.

Researchers had adopted TAM in various information system domain and considered this model as the most suitable model for the verification of an individual's initial acceptance. TAM was further extended by (Venkatesh \& Davis, 2000) by an accumulation of cognitive instrumental procedure and social influence procedure. However, they have a detached attitude from the basic model, because of the weak prediction of system usage or behavioural intention. Hence, the current study will integrate TAM with EECM to verify the continuance use intention of the user toward MLA in an evolving nation. 


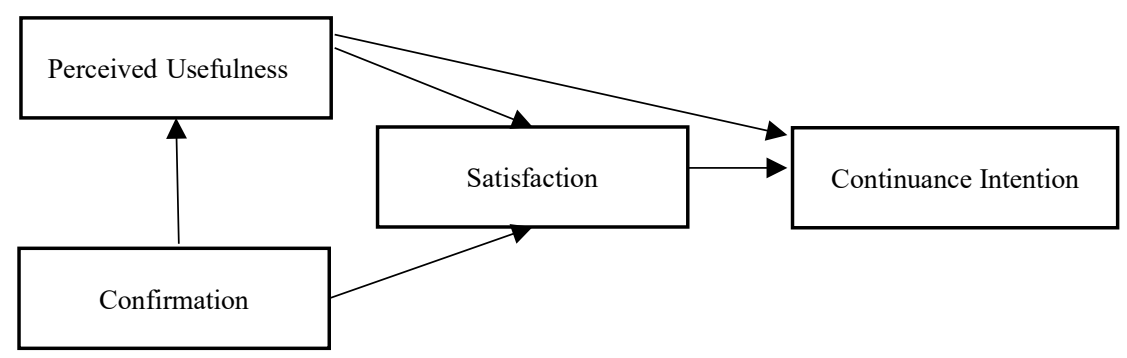

Fig. 1: Post-adoption model by Bhattacharjee

\subsection{An integrated model of EECM with TAM}

The proposed model is constructed on the foundation of (Bhattacherjee, 2001a). This model proposed that the extension of EECM will give improved involvement toward IT use to report the feebleness of the elementary model. As discussed in the literature, few studies used EECM extensions. Hence, we are going to implement the EECM integrated with TAM in MLA setting, and to the finest of our information, this is the first study of its kind with a focus on the continuance use of MLA, i.e., INSIGNIA ILS in an educational sector of an emerging country. We have integrated PEOU from TAM (Davis, 1989), service quality of information system success theory (ISST) (Delone \& McLean, 2003)(DeLone \& McLean, 1992) and MLA affinity from media affinity theory (Perse, 1986) in EECM. The purpose of adding PEOU, service quality and MLA affinity in EECM is to measure the ease of use of MLA by the user in their educational routine e.g., either in a library, university or while travelling, as it will affect the continuance usage of MLA. Similarly, if the provided service quality of MLA is not up to the mark then it will affect the importance of MLA affinity, which will ultimately affect the continuance use of MLA. Hence, it will help us in getting closer look toward the continuance use of MLA by observing at its ease of use, service quality and importance of MLA. Besides that, TAM focuses on initial acceptance than continuance usage, therefore, this proposed model will focus on both perspectives, i.e., initial acceptance and continuance usage by keeping service quality and media importance in focus. Hence, it is a need of an hour that we should explore the ease factor with the help of service quality and affinity of MLA to enhance the continuance usage of technology in the IT sector, particularly in library settings. Based on these reasons, we proposed the integration of two models, i.e., EECM and TAM along with factors from ISS and affinity theory, i.e., service quality and MLA affinity in order to clarify the MLA continuance intention.

\section{Research model and hypothesis}

Expectation confirmation model is the ground of this entire developed model, because of its capability of measuring the expectation of individual through their satisfaction along with the addition of new predictors in this model. Due to integration, the study will predict that the proposed model will better help us in excavating into the understanding of continuance usage intention of MLA in developing countries. We projected the holistic study model by covering the EECM and merging it with the feature from TAM, ISST and affinity theory. The proposed theoretical model is shown in Fig. 2, which is presenting the integrated factors along with the proposed hypothesis, to clarify the continuance intention applied to end-user while using MLA. In the projected model, continuance usage intention is the dependent variable, while perceived ease of use, perceived usefulness, satisfaction and MLA affinity are partial independent as they are also acting as the mediating variables and service quality along with confirmation are the fully independent variables. Demarcation of each factor is defined in Table 3. This section is further discussing the corresponding hypothesis of each factor along with the literature review of each factor. 
Service quality refers to as service features like responsiveness, dependability, empathy, assurance, reliability, personalization, prompt, reliable and professionalism that decreases the human energies while searching information through MLA (F. Xu \& Du, 2019). Service quality was adopted from ISS theory developed by (Delone \& McLean, 2003)(DeLone \& McLean, 1992), with arguments that, besides information and system quality, service quality is also the main predictor to user satisfaction on information systems. ISS was adopted in many areas of research including social networking community (Z. Zhang, 2009), the internet of things (Shin, 2017), and multi-platform services (Shin \& Shim, 2017)(Alzahrani, Ahmed Ibrahim and Mahmud, Imran and Ramayah, Thurasamy and Alfarraj, Osama and Alalwan, 2019).

Recently, the theory of ISS was applied in the domain of a digital library. Researcher (Chang, 2013a) discovered that three main determinants of ISS theory were the key predictor to satisfaction and perceived value among e-learning system located in academic libraries. However, the focus of this study was MLA which is used by the librarian community, students, researchers and teachers. Similarly, researcher (Zha, Xiao, \& Zhang, 2014), implemented ISS theory to discover the effect on the quality of digital libraries' and digital library affinity. Like prior study, their focus of interest is the digital library which is time and location dependent. Hence, it can be concluded that the prior research had made contributions in the application of ISS theory in a digital library arena for the identification of the influence of information, system and service quality on the satisfaction of the user. Therefore, by considering the characterisation of service quality from prior studies, this study hypothesized the consequence of service quality on MLA affinity, usefulness and perceived ease of use toward the continuance use of INSIGNIA ILS.

H1a: Service quality will have a significant positive influence on MLA affinity.

H1b: Service quality will have a significant positive influence on perceived usefulness.

H1c: Service quality will have a significant positive influence on perceived ease of use.

The positive effect of confirmation on satisfaction suggests the understanding of the likelihood of an IS use. It is demarcated as, "perception of a user for predictable benefits of MLA use and its real presentation" (Bhattacherjee, 2001a). The EECM postulates that confirmation from the user will have optimistic consequences on perceived usefulness of IT and the positive relationship was drawn on satisfaction from confirmation with IS use, as it deduces the understanding of the projected payback of IS use. Authors in (Lin \& Wang, 2012) empirically authenticated the effect of confirmation on satisfaction and perceived usefulness in web base e-learning environment. However, their study does not cover the aspects of mobile application, i.e., MLA, which is in use by the graduate research students. Similarly, research conducted at a national-level digital library in Taiwan shows the validation of confirmation toward all the mediating factors (Cheng, 2014). Their research focus is on the digital library which is under the spatial and temporal constraints. Therefore, their research needs to be extended in MLA context. Hence, in MLA context, a user confirms their benefits and expectation toward the use of the application which will influence PU and when they will get ease while using the system, then their confirmation of belief in the direction of the system will describe the satisfaction with the system (Cheng, 2014)(Moorthy et al., 2019). Therefore, this research projected the following hypothesis to inspect the effect of confirmation of users' continuance intention to use INSIGNIA ILS.

H2a: Confirmation will have a positive significant effect on perceived usefulness.

$\mathrm{H} 2 \mathrm{~b}$ : Confirmation will have a positive significant effect on satisfaction.

$\mathrm{H} 2 \mathrm{c}$ : Confirmation will have a positive significant effect on perceived ease of use.

Table 3: Definitions of Factors

\begin{tabular}{llll}
\hline Sr.\# & Factor Name & Definition & Source \\
\hline
\end{tabular}




\begin{tabular}{|c|c|c|c|}
\hline 1 & $\begin{array}{l}\text { Service } \\
\text { Quality }\end{array}$ & $\begin{array}{l}\text { service features like responsiveness, dependability, empathy, assurance, } \\
\text { reliability, personalization, prompt, reliable and professionalism that } \\
\text { decreases the human energies while searching for information through } \\
\text { MLA. }\end{array}$ & (F. Xu \& Du, 2019) \\
\hline 2 & MLA Affinity & $\begin{array}{l}\text { professed importance of mobile library application and its content in } \\
\text { users view toward their research and learning tasks }\end{array}$ & (F. Xu \& Du, 2019) \\
\hline 3 & Confirmation & $\begin{array}{l}\text { perception of users for expected paybacks of MLA use and its real } \\
\text { presentation. }\end{array}$ & $\begin{array}{l}\text { (Bhattacherjee, } \\
\text { 2001b) }\end{array}$ \\
\hline 4 & $\begin{array}{l}\text { Perceived } \\
\text { usefulness }\end{array}$ & $\begin{array}{l}\text { the degree to which an individual trust that using a specific system } \\
\text { would improve their job routine. }\end{array}$ & (Davis, 1989) \\
\hline 5 & $\begin{array}{l}\text { Perceived Ease } \\
\text { of Use }\end{array}$ & $\begin{array}{l}\text { the degree to which an individual think that using a specific system } \\
\text { would be effort-free. }\end{array}$ & (Davis, 1989) \\
\hline 6 & Satisfaction & $\begin{array}{l}\text { the cognition, emotional and sensational comeback towards the service } \\
\text { delivered by a Web-based IS. }\end{array}$ & (Yoon, 2016) \\
\hline
\end{tabular}

Media affinity was proposed for the evaluation of individuals' attitude towards the content of the media as well as on media (Perse, 1986). It can be abstracted using the perceived importance of the media rendering to persons individual life experience (F. Xu \& Du, 2018). Prior researches highlighted the influence of media affinity on future use intentions and media dependency (Ruiz Mafé \& Sanz Blas, 2006). Currently, very limited researcher implemented media affinity in the domain of digital library. Rendering to (Zha et al., 2014), digital library affinity was considered as the most influencing construct toward the effectiveness of the digital library. Similarly, (F. Xu \& Du, 2018) used affinity in a digital library context, and according to their study, the effect of affinity is stronger on usefulness than on user satisfaction. However, the limitation of all the relevant studies is that they targeted digital library in a context which is developed and advance in adoption of digital library and their targeted audience was not relevant to mobile library application.

Therefore, the current study conceptualized mobile library application affinity (MLA Aff) as "professed importance of mobile library application and its content in user view toward their research and learning tasks" (F. Xu \& Du, 2019). Therefore, librarians and service providers must provide error-free, efficient and high-quality service to their user. It was evidenced by the literature that; service quality affected DL's affinity (Zha et al., 2014). For example, if MLA will not provide a quality data and services then a user might observe that the library is lacking in providing quality services, which ultimately affect perceptions of the user toward the importance of MLA by affecting the level of continuance use of MLA. Hence, by keeping the scenario in mind, the research drew the following hypothesis

H3a: Mobile library application affinity will have a significant positive effect on perceived usefulness. H3b: Mobile library application affinity will have a significant positive effect on satisfaction.

Perceived usefulness is the core construct of TAM, which was adopted by (Bhattacherjee, 2001b) in EECM. It is demarcated as "the degree to which an individual trusts that using a specific system would improve their job routine." (Joo \& Choi, 2016). PU is considered as a vital antecedent in defining intention to use information system in TAM-based studies. Past studies validated the noteworthy influence of PU to satisfaction and continuance use intentions toward the systems by targeting library context (Yoon, 2016)(Ahmed, Zahid, Wajid, Muhammad, \& Vighio, 2019). However, most of the studies focused on general mobile application usage instead of applications that are used for educational purposes like MLA or m-learning, etc., Also, the usefulness of a system can affect users' feelings and intentions after completion of the task with it, which can be defined as satisfaction (Bhattacherjee, 2001b). Therefore, satisfaction is directly related to the usefulness of an information system. Accordingly, the current study proposed the following hypothesis:

H4a: Perceived usefulness will have a positive significant effect on satisfaction. 
H4b: Perceived usefulness will have a positive significant effect on continuance use intention.

Perceived ease of use (PEOU) is an integrated factor of the study. According to the current study, it can be elaborated as "the degree to which an individual thinks that using a specific system would be effort-free while using MLA" (Davis, 1989). PEOU is considered as the most important factor in defining the satisfaction of the user, if and only if technology reduces the mental stress of the intended user, then it will lead the user toward the continuance use of the application. Therefore, from the literature, it proved that PEOU is the predictor for the continuance usage of application as well as the good mediator for satisfaction which leads to continues use (Omotayo \& Haliru, 2019)(Thong, Hong, \& Tam, 2006). However, besides that, literature is not presenting the strong association of PEOU with satisfaction and continuance usage, as it is showing the acceptance of the relation at the marginal acceptance rate of P-value. Hence, keeping this concept in mind, this study demarcated its hypothesis toward the continuance use of INSIGNIA ILS as

H5a: Perceived ease of use will have a positive significant effect on satisfaction.

H5b: Perceived ease of use will have a positive significant effect on continuance usage intention.

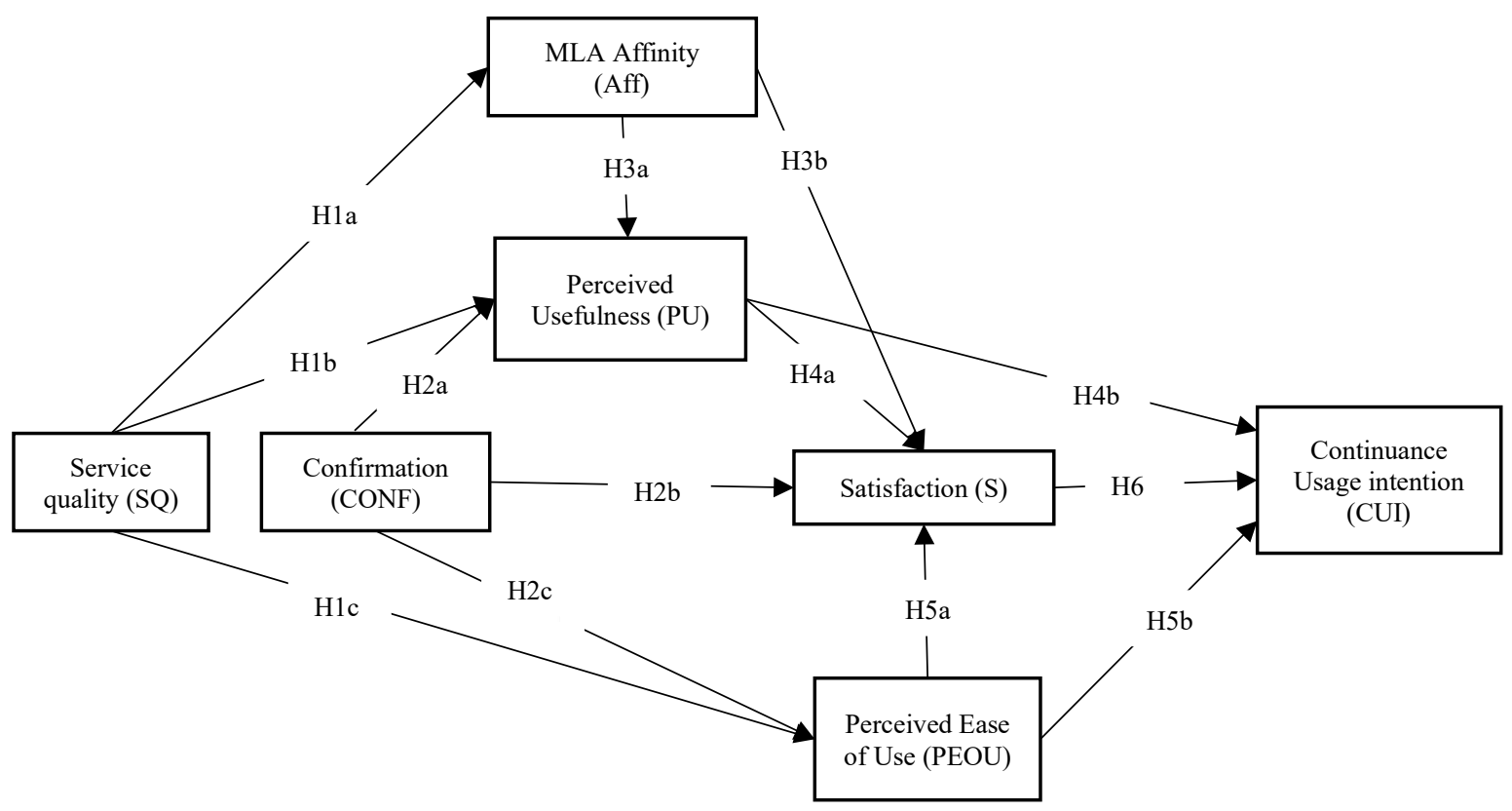

Fig. 2: Research Model

Previous research studies identify the optimistic affiliation of satisfaction on user intention toward a particular system. Research conducted by (Zhonggen \& Xiaozhi, 2019) states that the satisfaction of a user is influencing an intention to use digital library facilities. In the same way, (Rafique et al., 2018) clarified the connection of satisfaction by representing a significant effect on behaviour intention to use mobile communication. Results of (Yoon, 2016) state the substantial effect of satisfaction on intention to use MLA. However, the focus of these studies is on the initial acceptance of the application instead of continuance usage. The study conducted by (Ju et al., 2017) derived the relationship of satisfaction on continuance usage, however, the relationship is accepted on the marginal P-value, i.e., 0.05 . Their study does not show the strong bonding of satisfaction with continuance usage intention. Similarly, researcher (Malik \& Rao, 2019) proposed the relationship of satisfaction on continuance usage. Besides the strong mediating effect, it is showing a normal effect on continuance usage between the P-value of 0.01 . Therefore, this study conjectured the subsequent 
association of satisfaction on continuance use intentions.

H6: Satisfaction will have a positive significant effect on continuance usage intention.

\section{Research Method}

\subsection{Tool Development}

The initial most important step of conducting quantitative research is the development of a relevant instrument. The instrument is the basic tool for gathering data from the intended user with the base for rationalizing the results. Hence, by keeping the importance of the instrument, it is necessary to ensure the reliability, as well as the validity of the projected measurement items for each construct. So, all the items were picked from the pertinent works. Our developed instrument was divided into two major chunks. In the opening segment, demographic information was gathered with the primary focus on age, gender and qualification level of the user. Qualification is the important factor of this section, as it will help us in identifying the permanent or continuous user of INSIGNIA ILS, i.e., either it is undergraduate or postgraduate students. However, the second section of the developed instrument focuses on the questions related to constructs. Four items for service quality and three items of MLA affinity was selected from (F. Xu \& Du, 2018). Six items for perceived usefulness and six items of perceived ease of use were selected from (Rafique et al., 2018)(Rafique et al., 2020) respectively, confirmation construct was supported with four items from (Bhattacherjee, 2001a), four items for satisfaction are selected from (Cheng, 2014) and three items of continuance usage intention were selected from (Ye, Luo, Chen, Guo, \& Wei, 2019). Items used for each construct are elaborated in Table 4 below. Continuance usage intention is the emphasis of study; therefore, it is a dependent variable. Whereas, PEOU, PU, MLA affinity and satisfaction are the mediating independent variables. Service quality and confirmation are fully independent variables in the study.

Incorporated factors of the current study were used in the existing literature within various areas as described in the literature evaluation, meaning that, all the items for selected constructs were rearticulated according to the context of the study, i.e., INSIGNIA ILS mobile library application. Rephrased constructs were gauged by the expert faculty members for making the questionnaire understandable. Besides that, a pilot study was also directed to gauge the tool to get a vibrant picture of the instrument. The pilot study is a process for getting the understandability of layman / end-user of the IS/IT. In this scenario, undergraduate and postgraduate students are the end-users. For this, 20 random frequent users of MLA, i.e., ISLIGNIA ILS were selected from the CUI library database list. A pilot study was conducted in a library setting, with a response rate of $100 \%$. It was performed by the distribution of questionnaires to graduate and postgraduate students. It helps us in the evaluation of psychometric properties as well as in understanding the weakness of the questionnaire. All the suggested changes were incorporated in the final survey instrument before collecting the data. For example, one of the respondents said, if the audience of the study will be $\mathrm{MS} / \mathrm{PhD}$ students, then it will give an appropriate picture of the study, as they have more concern with mobile library application to get research-related knowledge. Another respondent suggested that, instead of explaining INSIGNIA ILS in the introduction section, write this name in every item as an alternative to MLA. One of the responses was funny. According to that, the author should give chocolate as a reward to the respondents, as they were sparing time for your study and it was implemented by the author. 
Table 4: Constructs, Items and source

\begin{tabular}{|c|c|c|c|}
\hline Constructs & Items & Measures & Source \\
\hline \multirow{4}{*}{$\begin{array}{l}\text { Service Quality } \\
\text { (SQ) }\end{array}$} & SQ1 & INSIGNIA ILS in our university provides on-time services. & \multirow{4}{*}{$\begin{array}{l}\text { (F. Xu \& Du, } \\
2018)\end{array}$} \\
\hline & SQ2 & $\begin{array}{l}\text { INSIGNIA ILS in our university provides prompt responses to my } \\
\text { questions. }\end{array}$ & \\
\hline & SQ3 & INSIGNIA ILS in our university provides personalized services. & \\
\hline & SQ4 & INSIGNIA ILS in our university provides professional services. & \\
\hline \multirow[t]{3}{*}{$\begin{array}{l}\text { MLA Affinity } \\
\text { (Aff) }\end{array}$} & Aff1 & $\begin{array}{l}\text { Seeking information through INSIGNIA ILS in our university is one } \\
\text { of my main daily activities. }\end{array}$ & \multirow[t]{3}{*}{$\begin{array}{l}\text { (F. Xu \& Du, } \\
2018)\end{array}$} \\
\hline & Aff2 & INSIGNIA ILS in our university is important in my life. & \\
\hline & Aff3 & $\begin{array}{l}\text { I cannot go for several days without seeking information from } \\
\text { INSIGNIA ILS library application in our university. }\end{array}$ & \\
\hline \multirow[t]{6}{*}{$\begin{array}{l}\text { Perceived } \\
\text { Usefulness (PU) }\end{array}$} & PU1 & $\begin{array}{l}\text { Using INSIGNIA ILS in my academia would enable me to access the } \\
\text { library more quickly. }\end{array}$ & \multirow[t]{6}{*}{$\begin{array}{l}\text { (Rafique et al., } \\
\text { 2018) }\end{array}$} \\
\hline & PU2 & Using INSIGNIA ILS would improve my academic performance & \\
\hline & PU3 & Using INSIGNIA ILS would make it easier to search library shelves. & \\
\hline & PU4 & $\begin{array}{l}\text { Using INSIGNIA ILS will enhance my effectiveness in searching } \\
\text { relevant contents. }\end{array}$ & \\
\hline & PU5 & I would find INSIGNIA ILS useful in my library search. & \\
\hline & PU6 & $\begin{array}{l}\text { Using INSIGNIA ILS in my academia would enable me to access the } \\
\text { library more quickly. }\end{array}$ & \\
\hline \multirow{6}{*}{$\begin{array}{l}\text { Perceived Ease } \\
\text { of Use (PEOU) }\end{array}$} & PEOU1 & Learning to use INSIGNIA ILS would be easy for me. & \multirow{6}{*}{$\begin{array}{l}\text { (Rafique et al., } \\
\text { 2020) }\end{array}$} \\
\hline & PEOU2 & I would find it easy to get INSIGNIA ILS to do what I want to do. & \\
\hline & PEOU3 & $\begin{array}{l}\text { My interaction with INSIGNIA ILS would be clear and } \\
\text { understandable }\end{array}$ & \\
\hline & PEOU4 & I would find INSIGNIA ILS to be flexible to interact with. & \\
\hline & PEOU5 & It is easy to become skilful at using INSIGNIA ILS. & \\
\hline & PEOU6 & I find INSIGNIA ILS easy to use. & \\
\hline \multirow[t]{4}{*}{ Satisfaction (S) } & $\mathrm{S} 1$ & Overall, I am satisfied with INSIGNIA ILS applications & \multirow[t]{4}{*}{ (Cheng, 2014) } \\
\hline & $\mathrm{S} 2$ & The INSIGNIA ILS that I am using now meets my expectations & \\
\hline & $\mathrm{S} 3$ & The INSIGNIA ILS is a beneficial tool in improving life & \\
\hline & $\mathrm{S} 4$ & Using INSIGNIA ILS is a pleasing experience for me. & \\
\hline \multirow[t]{5}{*}{$\begin{array}{l}\text { Confirmation } \\
(\mathrm{CONF})\end{array}$} & CONF1 & $\begin{array}{l}\text { My experience with using INSIGNIA ILS was better than what I } \\
\text { expected. }\end{array}$ & \multirow[t]{5}{*}{$\begin{array}{l}\text { (Bhattacherjee, } \\
\text { 2001a) }\end{array}$} \\
\hline & CONF2 & $\begin{array}{l}\text { The service level provided by INSIGNIA ILS was better than what I } \\
\text { expected. }\end{array}$ & \\
\hline & CONF3 & $\begin{array}{l}\text { Overall, most of my expectations from using INSIGNIA ILS were } \\
\text { confirmed. }\end{array}$ & \\
\hline & CONF4 & $\begin{array}{l}\text { Majority of expectations are satisfied when using INSIGNIA ILS } \\
\text { app. }\end{array}$ & \\
\hline & CONF5 & My expectations were satisfied with the provided application. & \\
\hline \multirow{3}{*}{$\begin{array}{l}\text { Continuance } \\
\text { Usage Intention } \\
\text { (CUI) }\end{array}$} & CUI1 & $\begin{array}{l}\text { I intend to continue using INSIGNIA ILS service during my study } \\
\text { period }\end{array}$ & \multirow{3}{*}{$\begin{array}{l}\text { (Ye et al., } \\
\text { 2019) }\end{array}$} \\
\hline & CUI2 & I will always try to use INSIGNIA ILS service in my educational life. & \\
\hline & CUI3 & I plan to continue to use INSIGNIA ILS service frequently. & \\
\hline
\end{tabular}

\subsection{Data Gathering}

As the subject of this study was CUI students, therefore, the study was conducted there. CUI is a topranked university of Pakistan, bestowing to the higher education commission (HEC) of Pakistan, it is in top 10 universities in the country and it is at number 1 in IT sector, However, according to the world ranking, it is in between 601-800 (“CUI Ranking and Reputation.," 2020)(“University Ranking in Pakistan,” 2020). CUI has 7 campuses across the country with 98-degree programs, $34000+$ enrolled students including $700+\mathrm{PhD}$ and $5000+$ MS students. The quantitative cross-sectional survey-based study was conducted at CUI. Data for this 
study were collected during spring 2019 semester, i.e., February 2019 to June 2019. Data were collected against 7 points Likert scale fluctuating from strongly disagree (7) to strongly agree (1). Respondents were requested to respond according to their understanding against the scale of the instrument. RAND function was used to select the random user from the provided list of CUI library officials, with the details including contact number, email address and education level. The list was first converted into excel format for creating a random number table. After that, 400 users were approached by the researcher through proper channel, i.e., by making an appointment through call. After eliminating the invalid responses, 307 responses were used for final analysis. Response with same answers against all items, response with the same patterns and response with maximum missing values were dropped before encoding the data. 40 collected instruments were having almost same answer pattern, 15 responses were eliminated due to missing values (reason behind this might be that there were few technical terms regarding INSIGNIA ILS app, which they might not be able to pick), 18 responses were discarded because of the same answers and 20 questionnaires were not returned to the author. Hence, total $76.75 \%$ responses were selected for further analysis, which is much more than the recommended sample size, i.e., 100-150 to implement structural equation model (SEM) for reliable results (Hair, Black, Babin, \& Anderson, 2010).

Description concerning the demographic information is presented in Table 5. According to the data, 58.6\% were male and $41.4 \%$ were female. Students between $26-30$ years of age responded the maximum, i.e., $53.4 \%$ followed by $32.2 \%$ from the age between $31-35$ years. In the context of qualification, the maximum response rate was from MS graduates, i.e., 173 responses with $56.5 \%$, followed by 100 responses from $\mathrm{PhD}$ with a percentage of 32.6. The reason behind the maximum response rate from MS/PHD students is that researcher targeted postgraduate students as they have most concern with the library and they might be the frequent user of INSIGNIA ILS. However, few students of undergraduate studies were also randomly selected out of which 28 students i.e., 9\% participated in this study. It was done to know the inclination of undergraduate students toward the continues use of academic library applications. Hence, a smaller number of participants proved that undergraduate students are not much inclined toward the use of library application. While elaborating the usage of the application in term of qualification level, data from the logbook of INSIGNIA ILS that was collected from the CUI library shows that students at the degree level of MS are frequent users of library app followed by $\mathrm{PhD}$ researchers. It is because MS students are new to research domain and being a new researcher, students try to learn and access more articles, thesis, e-books etc, from various tools as compared to PhD researcher who has vast experience in research.

\section{Data Analysis}

Data analysis is the procedure which helps in organizing, structuring, interpreting and presenting the raw data to useful information with the understanding of the data context (Hair et al., 2010). Therefore, to get a deep understanding of the data, the current study adopted two different types of software to perform data analysis, i.e., SPSS and AMOS. Initial analysis of data was performed using SPSS, i.e., coding of data, cleaning of the data by removing missing values and outlier, checking the assumptions, and by factor analysis. Whereas, reliability of data, the validity of data, discriminant validity of data and fit indices in measurement model (MM) along with the testing of projected hypothesis through structural model (SM) were performed in AMOS. A pictorial description of the adopted tactic is publicised in Fig. 3 below.

\subsection{Data Screening}

It is a method for ensuring the cleanliness of the encoded data before further analysis. Data screening helps us in testing the usability, data accuracy and reliability of the coded data. At this stage, data screening ensured (i) type of missing values, (ii) identifies outliers, and (iii) data normality. All the data screening steps are explained one by one below. 
Table 5: Respondent profile

\begin{tabular}{llll}
\hline Demographic factors & Categories & Frequency & Percentage (\%) \\
\hline Gender & Male & 180 & 58.6 \\
& Female & 127 & 41.4 \\
Age & $20-25$ years & 32 & 10.4 \\
& $26-30$ years & 164 & 53.4 \\
& $31-35$ years & 99 & 32.2 \\
& $36-40$ years & 8 & 2.5 \\
Qualification Enrolled & Above 41 & 4 & 1.2 \\
& BS & 28 & 9.1 \\
& MS & 173 & 56.4 \\
& PhD & 100 & 32.6 \\
\hline
\end{tabular}

\subsection{Missing value}

Issues of missing value arise when the respondent did not respond to the questions, which ultimately interrupt the outcome. Therefore, to overcome the hazardous effects on the results, it is obligatory to pattern the nature of the missing data, for which Little's Chi-square test was performed. The test portrayed the missing completely at random nature (MCAR), with Little Chi-square value 0.98 which is bigger than 0.05 . Hence, to substitute the lost values from the data, the researcher applied the "regression imputation" technique.

\subsection{Outlier detection}

Outliers are the values in a data set which might be far from the mean value. Therefore, we can say that "an outlier is a data point that fluctuates meaningfully from other annotations". Its occurrence in the data might be because of input error or may be due to the variability during the measurement which might result in catastrophic problems in analysis. So, outliers in the current study were identified at multivariate and univariate level with the help of Mahalanobis distance $\mathrm{D}^{2}$ and Z-score test, respectively. So, according to the statistical rules, data is measured as an outlier at multivariate level, if the value of $\mathrm{D}^{2} / \mathrm{DF}$ is superior to 3-4 (Hair et al., 2010) and data will be defined as an outlier at the univariate level if the value is 3 standard deviation away from a mean value. From the retrieved value of the data set, it is inferred that values are within 3 standard deviations for univariate outliers and for the multivariate level it is below 3, showing the mild nature of the outliers. Hence, to generalize the results of the study, outliers were kept in the study.

\subsection{Data normality}

Normality test is the process of checking the demonstration of the data with the help of a normal distribution curve. Normality was patterned at a univariate level by utilizing the assistance of kurtosis with the range \pm 3 and skewness with the range \pm 1 . The obtained result of the data presents the values of kurtosis and skewness lies within the defined range. Therefore, inferred results were not drastically conflicting with the normal distribution of the data.

Furthermore, factor analysis (FA) was performed on the data. It was directed to get the explanation of a large data pool by transforming it into the minor set of components. FA has two steps: exploratory factor analysis (EFA) and confirmatory factor analysis (CFA). This study used two types of software, EFA was performed using SPSS and CFA was conducted in AMOS along with the reliability and the validity of the constructs to perform hypothesis testing using SEM. The reason behind the usage of SEM is that it is adequately proficient for the estimation of the structural relationship between constructs, i.e., confirmation, PU, PEOU, satisfaction, service quality, MLA affinity and continuance intention to use, with numerous measurement items in the multivariate situation (Li, Chung, \& Fiore, 2017).

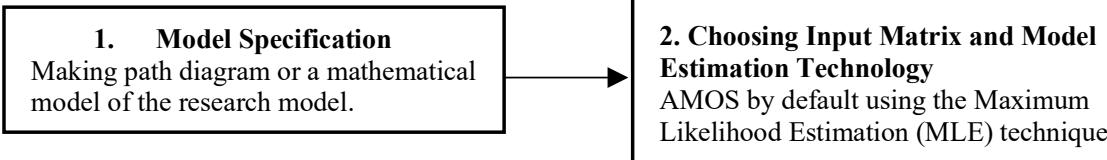

4. Estimation

a) Sample size checking

b) Data Normality

c) Outlier (Check mahala Nobis distance where $\mathrm{p} 1$ and $\mathrm{p} 2$ values $<0.001)$

d) Multicollinearity (correlation score $\leq 0.09$ )

e) Offending estimate (check variance of each 
Fig. 3: Strategy for Data Analysis

\subsection{Structural Equation Model (SEM)}

Structural equation modelling is a statistical technique that helps us in analysing the structural relationships at the multivariate level. It measures the relationship between latent constructs and measured variables with the help of regression and FA (Hair et al., 2010)(Scherer, Ronny and Siddiq, Fazilat and Tondeur, 2019). To perform the analysis using SEM technique, a recommend approach was adopted (Anderson \& Gerbing, 1988). Their method states the two-step tactic, i.e., measurement and structural model (MM and SM). The primary approach will use CFA technique in AMOS for the identification of association amongst observed and 
unobserved variables. Whereas, the second approach will help in the verification of the proposed null hypothesis drawn in the study between dependent and independent variables. In the end, SEM fitness was determined with the help of a coefficient parameter along with the goodness-of-fit indices (Byrne, 2001)(Hair et al., 2010).

\section{Results and Discussion}

As the adopted scales of this study have already been validated in many earlier studies with a strong theoretical foundation, therefore, the focus of study will be more on CFA than of EFA in evaluating the scale validity and reliability. However, a brief explanation of EFA is given below. Starting with the sample adequacy, all the observed variables must be purified before the analysis to get an improved understanding of the data. Therefore, purification of data was performed with the help of Kaiser-Mayer-Olkin (KMO) and Bartlett's test of sphericity during EFA with KMO $=0.903$ and Bartlett's $\mathrm{P}<0.001$, showing sample adequacy of the data intended for structure detection (Hutcheson \& Sofroniou, 1999). Furthermore, factor construction and factor extraction were performed. Factor construction was performed to get the factors with the factor loading higher than 0.7, which should be used for further analysis as recommended (Hair et al., 2010). It was performed with principal component analysis (PCA) by applying the varimax rotation. This rotation was used to extract the factors with higher loading instead of factors with less loading. As it helps in minimizing the number of variables which are having the major influence of the factors by ignoring the remaining correlations with little effect. Hence, factor rotation shows that extracted commonalities of all items except for PU6, CONF4 and CONF5 were above cut-off value i.e., 0.7. Total 28 remaining items were used in the further analysis as a new data set, as items with low factor loading as mentioned were removed at this stage of the analysis. Those items were removed to eliminate multiple loading, which was created by them is rotated component matrix to get the better alignment of the integrated factors with the constructed hypothesis. Hence after eliminated the items with lower commonalities, the new dataset was used in factor extraction. As in the second step, factor extraction was performed with the eigenvalue greater than one, with the total extraction of seven factors having overall $74.34 \%$ variance. Besides this, all the factors were reported on a 7-point Likert scale with a various number of items. E.g., According to Table 6, factor 1 have four items with $76.25 \%$ of AVE with the loading of a factor in between 0.71 to 0.81 . Factor 2 comprises of 3 items with $84 \%$ variance with loading between 0.71 to 0.92 . Similarly, factor 3,4,5,6,7 consists of items 5,6,4,3,3 with extracted variance as $65.99 \%, 76.47 \%, 60.57 \%, 61.19 \%$ and $67.37 \%$ with factor loading ranges between 0.79 to $0.84,0.79$ to $0.90,0.73$ to $0.82,0.72$ to 0.86 and 0.79 to 0.87 respectively. All the seven extracted factors will undergo further analysis through CFA by applying SEM technique in AMOS.

\subsection{Analysis of Measurement Model (MM)}

Before the evaluation of hypothesis, validity and reliability of each construct must be measured (Chin, 1998). Therefore, the reliability of items was checked with the help of composite reliability (CR), Cronbach's Alpha and average variance extracted (AVE). All the measurement items will be considered reliable if and only if the values of CR, Cronbach's Alpha and AVE are equal or higher than the threshold values, i.e., 0.7, 0.7 and 0.5 as recommended by (Straub, Detmar and Boudreau, Marie-Claude and Gefen, 2004). Table 6 enlisted the smallest attained values of CR, Cronbach's Alpha and AVE as 0.74, 0.822 and 60.57 respectively. All the obtained values are demonstrating the attained standard; therefore, all the constructs were reliable for the current study.

Furthermore, discriminant validity was confirmed. It was performed by taking the square root of AVE of key constructs along with the correlation matrix. As recommended by (Straub, Detmar and Boudreau, MarieClaude and Gefen, 2004), the obtained square root of AVE of every factor must be greater than the association of the explicit constructs with remaining constructs in the model. Hence, to strengthen the concept, Table 7 is representing the discriminant validity of the modelled constructs, by measuring the fitness of MM through three kinds of fit indices in SEM, i.e., (absolute, incremental and parsimonious) which are showing the acceptable values in Table 9 as recommended by (Byrne, 2001). 
Followed with the discriminant validity, factor loading was also measured for accessing the loading of the constructs, that either it is up to the accepted value or not. It is known as convergent validity. Table 6 is also representing the values of factor loading of each construct that is over the recommended value 0.7 , with acceptable convergent validity (Nunnally \& Bernstein, 1967)(Hair et al., 2010).

Table 6: Standardized item loadings, AVE, CR and alpha values

\begin{tabular}{|c|c|c|c|c|c|}
\hline Constructs & Items & $\begin{array}{c}\text { Factor } \\
\text { Loading }\end{array}$ & $\begin{array}{l}\text { Composite } \\
\text { Reliability }\end{array}$ & AVE & $\begin{array}{c}\text { Cronbach's } \\
\text { Alpha } \\
\end{array}$ \\
\hline \multirow[t]{4}{*}{ Service Quality (SQ) } & SQ1 & 0.71 & 0.79 & $76.25 \%$ & 0.876 \\
\hline & SQ2 & 0.74 & & & \\
\hline & SQ3 & 0.81 & & & \\
\hline & SQ4 & 0.79 & & & \\
\hline \multirow[t]{3}{*}{ MLA Affinity (Aff) } & Aff1 & 0.92 & 0.88 & $84 \%$ & 0.894 \\
\hline & Aff2 & 0.71 & & & \\
\hline & Aff3 & 0.89 & & & \\
\hline \multirow{5}{*}{$\begin{array}{l}\text { Perceived usefulness } \\
(\mathrm{PU})\end{array}$} & PU1 & 0.79 & 0.74 & $65.99 \%$ & 0.904 \\
\hline & PU2 & 0.80 & & & \\
\hline & PU3 & 0.84 & & & \\
\hline & PU4 & 0.84 & & & \\
\hline & PU5 & 0.79 & & & \\
\hline \multirow{6}{*}{$\begin{array}{l}\text { Perceived ease of use } \\
\text { (PEOU) }\end{array}$} & PEOU1 & 0.79 & 0.95 & $76.47 \%$ & 0.951 \\
\hline & PEOU2 & 0.84 & & & \\
\hline & PEOU3 & 0.90 & & & \\
\hline & PEOU4 & 0.89 & & & \\
\hline & PEOU5 & 0.91 & & & \\
\hline & PEOU6 & 0.91 & & & \\
\hline \multirow[t]{4}{*}{ Satisfaction (S) } & $\mathrm{S} 1$ & 0.73 & 0.86 & $60.57 \%$ & 0.822 \\
\hline & S2 & 0.82 & & & \\
\hline & S3 & 0.76 & & & \\
\hline & S4 & 0.80 & & & \\
\hline \multirow[t]{3}{*}{ Confirmation (CONF) } & CONF1 & 0.76 & 0.82 & $61.19 \%$ & 0.858 \\
\hline & CONF2 & 0.86 & & & \\
\hline & CONF3 & 0.72 & & & \\
\hline Continuance usage & CUI1 & 0.79 & 0.86 & $67.37 \%$ & 0.861 \\
\hline \multirow[t]{2}{*}{ Intention (CUI) } & CUI2 & 0.87 & & & \\
\hline & CUI3 & 0.80 & & & \\
\hline
\end{tabular}

Table 7: Discriminant validity

\begin{tabular}{llllllll}
\hline Correlations Squared & SQ & CONF & Aff & PU & S & PEOU & CUI \\
\hline Service Quality (SQ) & $\mathbf{0 . 7 6}$ & & & & & & \\
Confirmation (CONF) & 0.19 & $\mathbf{0 . 6 1}$ & & & & & \\
MLA Affinity (Aff) & 0.22 & 0.11 & $\mathbf{0 . 8 4}$ & & & & \\
Perceived usefulness (PU) & 0.31 & 0.24 & 0.29 & $\mathbf{0 . 6 6}$ & & & \\
Satisfaction (S) & 0.30 & 0.28 & 0.05 & 0.16 & $\mathbf{0 . 6 1}$ & & \\
Perceived Ease of Use (PEOU) & 0.25 & 0.29 & 0.07 & 0.10 & 0.09 & $\mathbf{0 . 7 6}$ & \\
Continuance usage Intention (CUI) & 0.12 & 0.18 & 0.21 & 0.36 & 0.13 & 0.08 & $\mathbf{0 . 6 7}$ \\
\hline
\end{tabular}

Note: Diagonal values are AVE and off-diagonal are inter-construct squared correlations. 
After finding the adequacy of a model through a measurement model, the proposed hypothesis was tested by analysing the structural model. The association among the hypothesis and constructs was explained with the coefficient of determination $\left(\mathrm{R}^{2}\right)$ and path coefficient in $\mathrm{SM}$ testing. $\mathrm{R}^{2}$ elucidates the prophecy supremacy of the constructs while path coefficient explicates the strong point of the projected hypothesis. Values of both $\mathrm{R}^{2}$ and path coefficient depict the data sustenance in the task of the conjectured model (Sang, Lee, \& Lee, 2010). Hence, the fitness of the projected model during SM was restrained with three sorts of fit indices in SEM, just like in MM. All the retrieved outputs of fit indices are depicting the statistical significance of data in SM as represented in Table 9 (Hair et al., 2010).

Fig 4 and Table 8 are explaining the output of SM with the explanation that, the paths are significant at $0.001,0.01$ or 0.05 . Excluding the path coefficient of PU at satisfaction, i.e., the hypothesis H4a, all the rest of the hypothesis were accepted. Therefore, it is clear from the output that, confirmation is directly manipulating PEOU, PU and satisfaction. Service quality is influencing MLA affinity, PU and PEOU. In addition to that, MLA affinity is affecting PU and satisfaction, followed by the effect of PEOU on satisfaction. Similarly, satisfaction, PU and PEOU are having a direct significant effect on continuance usage intention to use MLA, i.e., INSIGNIA ILS. While talking about the indirect effect on continuance usage intention, confirmation and service quality are having an indirect effect on continuance intention through the mediating variables. i.e., PU, MLA affinity, satisfaction and PEOU. Likewise, PEOU and MLA affinity are having an indirect effect on continuance usage through the mediating variable, i.e., satisfaction. AMOS represented the weakest positive relationship of MLA affinity on satisfaction and the effect of satisfaction on continuance usage intention (H3b: $\beta=0.226, \mathrm{P}<0.05)(\mathrm{H} 6: \beta=0.146, \mathrm{P}<0.05)$ respectively, followed by the slightly stronger effect of confirmation on satisfaction $(\mathrm{H} 2 \mathrm{~b}: \beta=0.210, \mathrm{P}<0.01)$. However, the rest of the hypothesis had strong significant effects. A confirmation had a scientifically strong effect on PEOU (H2c: $\beta=0.318, \mathrm{P}<0.001)$ than $\mathrm{PU}(\mathrm{H} 2 \mathrm{a}: \beta=0.300$, $\mathrm{P}<0.001)$. Likewise, the effect of PEOU on satisfaction and continuance usage intention is (H5a: $\beta=0.358$, $\mathrm{P}<0.001$ ) (H5b: $\beta=0.462, \mathrm{P}<0.001)$ respectively and $\mathrm{PU}$ showing the strong effect on $(\mathrm{H} 4 \mathrm{~b}: \beta=0.211, \mathrm{P}<0.001$ ). However, in context of service quality, it has the strongest effect on MLA affinity (H1a: $\beta=0.410, P<0.001$ ) and MLA affinity have a strong effect on perceived usefulness (H3a: $\beta=0.299, \mathrm{P}<0.001)$.

The variance of all the mediating and dependent variables was derived with the assessment from squared multiple correlations. The variance of a dependent variable, i.e., continuance usage intention is $38.9 \%$, mediating variables like PU, PEOU, satisfaction and MLA affinity are showing a variance of about $30.6 \%$, $30.2 \%, 28.3 \%$ and $29.8 \%$ respectively. Fitness of both MM and SM were measured with the help of three sorts of indices to check the best representation of data on the proposed model. Fit indices are absolute fit measure $(\chi 2$, root mean square error of approximation (RMSEA), goodness-of-fit-index (GFI), adjusted goodness of fit (AGFI)), Incremental fit measure (normed fit index (NFI) and Parsimonious fit measure (comparative fit index (CFI)). Three main kinds of indices were calculated for both MM and SM. It was done to represent the data significance toward the proposed model. All the fit measures along with the achieved and cut off values are represented in (Hairs, Anderson, Tatham, \& Black, 1998).

The further section will discuss all the hypothesis individually. All the proposed hypothesis is

H1a: SQ $\rightarrow$ Aff, H1b: SQ $\rightarrow$ PU, H1c: SQ $\rightarrow$ PEOU, H2a: CONF $\rightarrow$ PU, H2b: CONF $\rightarrow$ S, H2c:CONF $\rightarrow$ PEOU, H3a: Aff $\rightarrow$ PU, H3b: Aff $\rightarrow$ S, H4a: PU $\rightarrow$ S, H4b: PU $\rightarrow$ CUI, H5a: PEOU $\rightarrow$ S, H5b: PEOU $\rightarrow$ CUI, H6: S $\rightarrow$ CUI

\section{H1a: SQ $\rightarrow$ Aff, H1b: SQ $\rightarrow$ PU, H1c: SQ $\rightarrow$ PEOU}

Hypothesis H1a states that service quality has a significant and positive effect on MLA affinity, hypothesis $\mathrm{H} 1 \mathrm{~b}$ was demarcated with the strong noteworthy effect on perceived usefulness and H1c states the robust impression on PEOU. All the proposed hypotheses were defined accurate with the achieved results from data analysis $(\beta=0.410$, critical ratio $(\mathrm{CR})=4.010$ and $\mathrm{P}<0.001)(\beta=0.260, \mathrm{CR}=3.221$ and $\mathrm{P}<0.001)(\beta=$ $0.360, \mathrm{CR}=4.124$ and $\mathrm{P}<0.001)$ respectively. All the hypothesis was defined true because, the obtained values 
of $\mathrm{CR}$ and $\mathrm{P}$, are according to the threshold standards, i.e., $\geq 1.96$ and $\mathrm{P}<0.001$. However, among all the proposed hypothesis from service quality, H1a had the strongest influence on MLA affinity, which finally influences user satisfaction followed by the effect of service quality on PU and service quality on PEOU in hypothesis $\mathrm{H} 1 \mathrm{~b}$ and $\mathrm{H} 1 \mathrm{c}$ respectively. Therefore, it is said to be the strongest predictor in defining the satisfaction and continuance use of INSIGNIA ILS among the users. Obtained results are consistent with the prior research (F. Xu \& Du, 2018)(Zha et al., 2014). Hence, the proposed hypothesis was defined accurate according to the results.

\section{H2a: CONF $\rightarrow$ PU, H2b: CONF $\rightarrow$ S, H2c: CONF $\rightarrow$ PEOU}

According to the hypothesis, confirmation influences perceived usefulness with strong impact. Rendering to the statistical analysis $(\beta=0.300, \mathrm{CR}=4.515$ and $\mathrm{P}<0.001)$, hypothesis H1a, which states that confirmation has a strong positive effect on PU is confirmed as true. As CR and P-value are greater/or in range of the recommended value, i.e., $\geq 1.96$ and 0.001 , therefore, it is said to be the strongest predictor toward continuance usage of INSIGNIA ILS. Results of this study are like the results from (Ye et al., 2019)(Malik \& Rao, 2019). Hence, the proposed hypothesis is considered as a significant hypothesis.

Secondly, according to the effects of confirmation on its all dependent variables, the effect of confirmation on satisfaction is the weakest one as compared to the effect on PU and PEOU. Although it is strongly significant with $(\beta=0.210, \mathrm{CR}=3.162$ and $\mathrm{P}<0.01)$, as it is clear from the statistics that, the worth of the critical ratio is superior to the verge, i.e., $\geq 1.96$ and the value of $P$ is less than the cut of value, i.e., $p \leq$ 0.01. Hence, the developed hypothesis which states the positive noteworthy effect of confirmation on satisfaction was accepted in favour of INSIGNIA ILS. Therefore, the results of $\mathrm{H} 2 \mathrm{~b}$ is parallel to the results of (Ye et al., 2019)(Malik \& Rao, 2019).

The third effect is directed from confirmation toward PEOU. Hypothesis H2c stats that, confirmation in the proposed study has a strong and significant influence on PEOU toward the continuance usage of INSIGNIA ILS. According to the readings obtained from the analysis $(\beta=0.318, \mathrm{CR}=4.924$ and $\mathrm{P}<0.001)$ shows the strong influence of confirmation on PEOU. It is therefore stated that confirmation is the main and important standard for the continuance usage of INSIGNIA ILS, with the results like the results of the existing studies (Malik \& Rao, 2019).

\section{H3a: Aff $\rightarrow$ PU, H3b: Aff $\rightarrow S$}

MLA affinity hypothesis is elaborated with a positive significant effect on PU and satisfaction. Both proposed hypotheses were considered accurate as statistical results of $\mathrm{H} 3 \mathrm{a}$ is $(\beta=0.299, \mathrm{CR}=4.162$ and $\mathrm{P}<$ $0.001)$ and for $\mathrm{H} 3 \mathrm{~b}$ is $(\beta=0.226, \mathrm{CR}=2.215$ and $\mathrm{P}<0.05)$. The obtained result represents the strong effect of affinity on usefulness than on the satisfaction. It is because the influence of affinity on usefulness is accepted at 0.001 of P-value whereas, the effect of affinity on satisfaction is accepted at the marginal value of P, i.e., 0.05. However, results are still consistent with the existing research (F. Xu \& Du, 2018)(Zha et al., 2014). The reason behind the weak acceptance of $\mathrm{H} 3 \mathrm{~b}$ might be that a user might not consider much about the medium, as maximum data were gathered from postgraduate students who are mostly interested in accessing research article or research knowledge instead of the usefulness of the medium. Hence, it can be said that a user of INSIGNIA ILS in Pakistan are much interested in research than the medium. 
Table 8: Hypothesis testing

\begin{tabular}{|c|c|c|c|c|c|c|}
\hline Constructs & Code & Hypothesis & Relationships & $\beta$ Value & C.R /t-value & Status \\
\hline \multirow[t]{3}{*}{ Service Quality } & SQ & H1a & SQ $\rightarrow$ Aff. & 0.410 & $4.010 * * *$ & Supported \\
\hline & & $\mathrm{H} 1 \mathrm{~b}$ & $\mathrm{SQ} \rightarrow \mathrm{PU}$ & 0.260 & $3.221 * * *$ & Supported \\
\hline & & $\mathrm{H} 1 \mathrm{c}$ & $\mathrm{SQ} \rightarrow \mathrm{PEOU}$ & 0.360 & $4.124 * * *$ & Supported \\
\hline \multirow[t]{3}{*}{ Confirmation } & CONF & $\mathrm{H} 2 \mathrm{a}$ & $\mathrm{CONF} \rightarrow \mathrm{PU}$ & 0.300 & $4.515 * * *$ & Supported \\
\hline & & $\mathrm{H} 2 \mathrm{~b}$ & $\mathrm{CONF} \rightarrow \mathrm{S}$ & 0.210 & $3.162 * *$ & Supported \\
\hline & & $\mathrm{H} 2 \mathrm{c}$ & $\mathrm{CONF} \rightarrow \mathrm{PEOU}$ & 0.318 & $4.924 * * *$ & Supported \\
\hline \multirow[t]{2}{*}{ MLA Affinity } & Aff & $\mathrm{H} 3 \mathrm{a}$ & Aff $\rightarrow$ PU & 0.299 & $4.162 * * *$ & Supported \\
\hline & & $\mathrm{H} 3 \mathrm{~b}$ & Aff $\rightarrow \mathrm{S}$ & 0.226 & $2.215 *$ & Supported \\
\hline \multirow[t]{2}{*}{ Perceived usefulness } & PU & $\mathrm{H} 4 \mathrm{a}$ & $\mathrm{PU} \rightarrow \mathrm{S}$ & -0.028 & -0.412 & Not Supported \\
\hline & & $\mathrm{H} 4 \mathrm{~b}$ & $\mathrm{PU} \rightarrow \mathrm{CUI}$ & 0.211 & $3.329 * * *$ & Supported \\
\hline \multirow[t]{2}{*}{ Perceived ease of use } & PEOU & $\mathrm{H} 5 \mathrm{a}$ & $\mathrm{PEOU} \rightarrow \mathrm{S}$ & 0.358 & $5.169 * * *$ & Supported \\
\hline & & $\mathrm{H} 5 \mathrm{~b}$ & PEOU $\rightarrow$ CUI & 0.462 & $6.728 * * *$ & Supported \\
\hline Satisfaction & $\mathrm{S}$ & H6 & $\mathrm{S} \rightarrow \mathrm{CUI}$ & 0.146 & $2.357 *$ & Supported \\
\hline
\end{tabular}

***: $\mathrm{p}<0.001, * *: \mathrm{p}<0.01, *: \mathrm{p}<0.05$

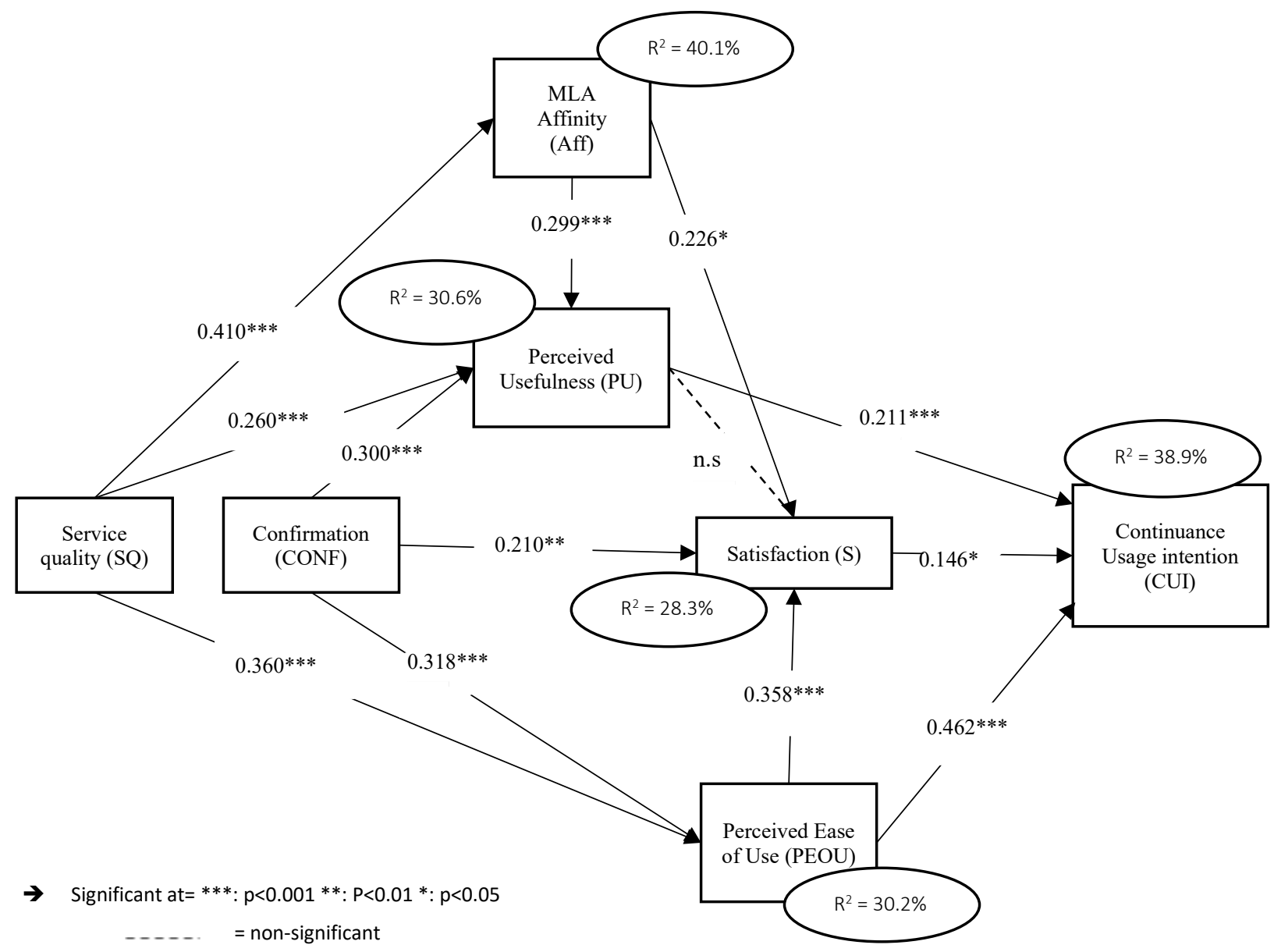

Fig. 4: Results of the analysis

Table 9: Summary of fit indices 


\begin{tabular}{llll}
\hline Absolute fit measure & & \\
Chi-square $\left(\chi^{2}\right)$ & & 229.116 & 303.258 \\
Df (Degrees of freedom) & & 171 & 173 \\
p-value (probability & $<0.05$ & & 1.753 \\
CMIN $(\chi 2) / D F$ & $<3$ & 1.340 & 0.924 \\
GFI (goodness of fit index) & $\geq 0.90$ & 0.940 & 0.049 \\
$\begin{array}{l}\text { RMSEA (root mean square error of } \\
\text { approximation) }\end{array}$ & $<0.5$ & 0.033 & 0.90 \\
$\begin{array}{l}\text { AGFI (adjusted goodness of fit index) } \\
\text { Incremental fit measures }\end{array}$ & $\geq 0.90$ & 0.918 & 0.938 \\
$\begin{array}{l}\text { NFI (normed fit index) } \\
\text { Parsimony fit measures }\end{array}$ & $\geq 0.90$ & 0.953 & 0.972 \\
CFI (comparative fit index) & & & \\
\hline
\end{tabular}

\section{H4a: PU $\rightarrow$ S, H4b: PU $\rightarrow$ CUI}

According to hypothesis H4a, PU should have a strong impact on satisfaction. However, according to the statistical analysis it does not stands true, as the result $(\beta=-0.028, \mathrm{CR}=-0.412$ and $\mathrm{P}>0.5)$ is not in favour of the hypothesis according to the recommended values. As it can be seen from the results that, the standard regression weight of the hypothesis is -0.028 and the CR value is less than 1.96, i.e., -0.412 and followed by the strongly rejected P-value that is much greater than 0.5 . Therefore, it became the reason for its rejection. The analysis result shows that users don't give importance to perceived usefulness as compared to other constructs while using INSIGNIA ILS in their study duration and hence, it does not show the significance of PU on continuance usage. Although prior studies show the significance of PU on CUI (Joo \& Choi, 2016)(Cheng, 2014). However, the reasons behind the conflicting results might be that user considered online or digital library resource more useful as compared to MLA, as they just have to type the query for their relevant search and besides that, searching online will give ease of access to recommended articles, e-books and e-library, etc., to the users. Another reason behind the rejection of this hypothesis might be that the internet penetration rate in Pakistan is lowered as compared to neighbouring nations, i.e. Saudi Arabia 29.21\%, Iran has 32\% and UAE has $86 \%$. Pakistan is investing a huge amount of budget to its IT sector and is expected that the IT sector will develop soon (Rafique et al., 2018). Result of hypothesis H4a is consistent with (Kim, 2010), showing that the users do not consider PU helping in continuous using of INSIGNIA ILS. Hence, it is alike to the current study who do not consider PU as a predictor for satisfaction in the continuance usage of mobile library application.

Hypothesis H4b states the positive influence of PU on continuance usage toward INSIGNIA ILS. Study shows that people considered usefulness as an important factor toward the continuance usage, which means that, usefulness must be considered during the development and use of MLA for the continuance use. According to the statistics of $\mathrm{H} 5 \mathrm{a}(\beta=0.211, \mathrm{CR}=3.329$ and $\mathrm{P}<0.001)$ hypothesis are strongly influencing continuance usage. Hence, the study results are in support of the existing results from (Ju et al., 2017), with the perspective that, users will continue using the application until and unless it is easy to use.

\section{H5a: PEOU $\rightarrow$ S, H5b: PEOU $\rightarrow$ CUI}

Conferring to the hypothesis H5a, PEOU has a strong noteworthy influence on satisfaction toward using INSIGNIA ILS continuous use. The CR value of the projected hypothesis is indeed higher than the threshold value, i.e., $\geq 1.96$ as shown by the statistics $(\beta=0.358, \mathrm{CR}=5.169$ and $\mathrm{P}<0.001)$. The outcomes of this hypothesis are clearly explaining the significant influence of PEOU on satisfaction and therefore it stands strong among the proposed hypothesis. Results of this hypothesis are in sequence to the existing studies (Cheng, 2014)(Ju et al., 2017)(Malik \& Rao, 2019).

The second hypothesis, i.e., H5b is emitted from PEOU on continuance usage intention. It is defined 
as, the effect of PEOU will be strong and significant on CUI toward the use of INSIGNIA ILS. It can be seen from the analysis that the values $(\beta=0.462, \mathrm{CR}=6.728$ and $\mathrm{P}<0.001)$ are all according to the endorsed standards and in favour of the defined hypothesis. Hence, the obtained results are in parallel with the existing studies (Malik \& Rao, 2019).

\section{H6: S $\rightarrow$ CUI}

According to the statement of influencing the relationship of satisfaction on continuance usage, it was defined that the satisfaction will have a strong and significant influence on continuance use of INSIGNIA ILS, nonetheless, statistical analysis is therefore against the hypothesis by showing $(\beta=0.146, \mathrm{CR}=2.357$ and $\mathrm{P}<$ 0.05). It means that, although the relationship is accepted, and it is having an influence on the dependent variable, but the influence of satisfaction is weak as defined by its P-value. However, still, it is showing an influence toward the continuance usage of the application, with the results consistent with (Cheng, 2014)(Malik $\&$ Rao, 2019) and hence the study is in favour of the acceptance regarding the hypothesis.

\section{Discussion}

Findings of the study confirm the importance of the extended expectation confirmation model. According to which, continuance usage of MLA, i.e., INSIGNIA ILS depends on the integrated factors namely perceived ease of use, service quality and MLA affinity. The developed model explained the decent fit of data along with the justification of the proposed associations. Fig. 4 represents the final model that is obtained after the analysis of the study along with the additionally added constructs. Hence, it can be determined from the facts that the addition of external factors have great importance in determining the continuance usage of MLA.

At first, service quality, confirmation and MLA affinity had noteworthy impressions on perceived usefulness. Hence, the obtained results are parallel to the existing finding in various contexts like mobile web and mobile commerce (F. Xu \& Du, 2018)(Ye et al., 2019)(Malik \& Rao, 2019). Achieved results can be used as a base by the librarians as well as by the developers to provide the better quality of services and designs along with the relevant tutorials particularly targeting undergraduate students to overcome their usage hesitation toward application, as they will be the perspective user of MLA in their graduate studies. In parallel to this, librarians should arrange guidance sessions, seminars or workshops every semester toward the practical use of the application after knowing the users' potential interest toward events. Those events should cover guidance regarding the retrieval of information from MLA within or outside the campus, e.g., accessing research articles, published thesis, e-books and other services of the library. It will help the user in saving time which they will spend in learning the MLA for their use. Moreover, librarians ought to strengthen discussions with the handlers to gain users data for cultivating the service quality. For example, librarians' needs' to be quick in response to the real-time queries from the user through communication tools like Facebook, WhatsApp, Twitter or WeChat etc. Besides, the librarian can also leverage users' preference, cookies data and location for personalized services to a user, which may help in increasing the usefulness of the MLA. Nonetheless, librarians need to gain prior consent from the user to evade any probable defilements of user confidentiality. Additionally, both librarians and service provider should support their user with personalized and professional information resources, because it helps in differentiating good mobile libraries and an inadequate one based on the quality of information and quality of services (F. Xu \& Du, 2018).

Secondly, both service quality and confirmation are influencing PEOU. In between both, service quality had a major effect on PEOU. Obtained results are consistent with the prior research discoveries among which service quality of digital library system meaningfully prejudiced the PEOU (F. Xu \& Du, 2018). Hence, the constructs relevant to MLA applications should be given significant importance for improving the service quality as well as for increasing the confirmation level of the user toward MLA applications. Meanwhile, both service provider and developers' need to deliver the finest interface, reliability and service quality to their user, so that it will help them to confirm their presence on MLA for a long period.

Thirdly, service quality had a strong influence on MLA affinity. The result is consistent with (F. Xu \& Du, 2018) work, with an explanation that the affinity using a digital library can surely present the meticulous nature 
of users' dependence and cognitive behaviour on digital library. Hence, developers should provide excellent designs of MLA with a clear layout, reliable system and effective navigation to ornamental the application quality, whereas, librarians should provide better guidance sessions to train their users.

Fourthly, confirmation, PEOU and MLA affinity had an important effect on satisfaction. Obtained outcomes are similar to the existing results in the context of digital library settings (F. Xu \& Du, 2018)(Ju et al., 2017)(Malik \& Rao, 2019). PEOU had a strong effect on user satisfaction followed by MLA affinity. Hence, keeping this context in focus, service providers, designers and developers should concentrate on ease of use of MLA along with effective user-friendly design and reliable system. Provided system and services should work efficiently and professionally along with the presentation of accurate, comprehensive and up-to-date information resources. Parallel to the effective design and resources, universities should organize seminars or workshops with guiding tutorials. It will create confidence and trust in user as they will consider the application ease to use and timesaving with results in continuance usage.

Lastly, PU, satisfaction and PEOU influenced continuance usage. Among the core constructs of TAM, PEOU had a strong impact on the continuance use of MLA. Similar results were found in previous studies (F. $\mathrm{Xu} \& \mathrm{Du}, 2018)(\mathrm{Ju}$ et al., 2017)(Malik \& Rao, 2019). Therefore, it is significant for the librarians and service provider to deliver the best possible services for their user to keep them on MLA for a long time, as continuance use depends on the satisfaction, PU and PEOU. If the user will feel satisfaction while using the best quality of services than the user will have strong confirmation toward the continuance usage of MLA, i.e., INSIGNIA ILS in this context.

This study also elaborated the non-significant effect of perceived usefulness on satisfaction, with one explanation that users are continuously using the application for their study and finding research articles which make them clear about the use of the application, hence they might not think about its usefulness. Although this result is strongly accepted in an existing study (Joo \& Choi, 2016)(Cheng, 2014), one explanation about this result might be that the majority of the targeted audience is postgraduate students who have more concern with a research article. Therefore, it can be assumed that they are more interested in the availability of the articles while on the move, instead of its usefulness. The second reason might be that librarians provide enough training and guidance to the user that they don't bother about the usefulness of the application. The third reason for the conflicting results might be that user considered online or digital library resource more useful as compared to MLA, as they just have to type the query for their relevant search and besides that, searching online will give access to recommended articles, e-books and e-library, etc., to the users. Indeed, usefulness is a much more important part of the users' satisfaction. Therefore, service providers should take a keen interest in providing better use of the application toward continuance use of the MLA. Research work (Kim, 2010) observed a similar result as of our study, which depicts that the outcomes of the current research are noteworthy as they show nonsignificance of perceived usefulness on satisfaction.

\section{Implications for research and practices}

\subsection{Theoretical implications}

University students in Pakistan are more interested in using google scholar, and other online e-libraries like, Science Direct, IEEE, ACM and Springer instead of using mobile library applications or digital libraries to access relevant information because of ease of use, convenience and simple interface (F. Xu \& Du, 2018). Hence, because of this, the student's intention and loyalty toward the digital or mobile library is decreasing. To overcome this threat, user satisfaction and confirmation can help in promoting the continuance use of mobile library applications (F. Xu \& Du, 2018). Current study reviled that, user satisfaction had a positive and significant effect along with the mediating strong effect on continuance use of mobile library applications.

Secondly, this research helps in improving the acquaintance of user satisfaction in mobile library applications' user satisfaction. Indeed, there has been a lot of research in the area of digital libraries while 
targeting user satisfaction; however, they were largely based on IT adopting theories, i.e., perceived interactivity (Yoon, 2016), TAM (Joo \& Choi, 2016), information system success theory (Cheng, 2014), and affinity (Zha et al., 2014)(Ruiz Mafé \& Sanz Blas, 2006). In the current research, researcher combined EECM, TAM, affinity theory and service quality for the identification of the factors which might create hurdles in the continuance use of mobile library application use in developing nation Pakistan. Indeed, it can help developers and researchers to get better and deep look toward the relationship of those factors which leads toward the continuance use of MLA (Ali, Shakil, Rafique, \& Cheema, 2019).

This study is first in its kind to investigate the continuance use of MLA in an evolving state, i.e., Pakistan, with the mediating effect of MLA affinity toward the continuance use with the integration of it with EECM and TAM. As it better explains the mediating effect of service quality toward continuance use of MLA.

\subsection{Implication for practice}

This study delivers some vision for facility providers and librarians to surge the continuance use of MLA. Our conclusions specify that continuance use of MLA depends on the user's satisfaction and confirmation. As both are showing a significant effect on continuance use either directly or through the satisfaction. Besides that, PEOU and affinity are showing a significant effect on continuance use through satisfaction. The core constructs of TAM, i.e., PU and PEOU are having a direct effect on continuance use toward MLA. Consequently, librarians along with facility providers must focus on these factors to increase the long-term usage of MLA among its users, e.g., librarians must arrange face-to-face guidance, seminars relevant to the benefits, service quality, accessibility and movability of mobile library applications. In addition to this, librarians must provide simple easy access for creating MLA account and they may even provide quick response to the queries of the user, which will help in the increasing the long-term usage of MLA among users.

\section{Conclusion}

Based on the inspiration of theories like EECM, TAM, MLA affinity and information system success, a survey was conducted to figure out the factors which might be affecting the continuance use of MLA among its users in Pakistani universities. According to the obtained results, perceived usefulness, PEOU and MLA affinity are positively affected by the service quality of MLA and confirmation of the users. Moreover, confirmation, service quality and MLA affinity had an important positive effect on PU. Besides that, MLA affinity and PEOU had a strong influence on satisfaction which is mediating their effect on continuance usage of MLA. It was also inferred from the results that, education level influence MLA affinity, PEOU, and satisfaction toward the continuance use of mobile library applications. Therefore, based on our finding, it can be concluded that integration of TAM, information system success theory and affinity theory can be used as an integrated model for understanding and predicting the influencing factors toward continuance use of MLA.

\section{Limitations and Future Work}

Obtained results are of worth importance, therefore, implementation of fallouts should be castoff with cautions because of the succeeding reasons. First and for most restriction of the research is the generalizability. Research was conducted in an evolving country Pakistan, where mobile library applications are developing with a fast pace but still is in the initial stage. Besides that, the collected sample does not contain cultural diversity in it, so it might not be generalized to other countries with diverse or multiple cultures. Secondly, the sample was collected from the university where mobile app penetration is very high and the users were educated, with maximum enrolment in postgraduate studies. Therefore, the outcomes of this study cannot be useful to the nations where the mobile penetration rate is low, and the audience is not well educated. Thirdly, our investigation particularly embattled MLA, i.e., INSIGNIA ILS. However, in forthcoming, our projected model can be implemented to various domains in developing as well as in developed counties, i.e., in the field of eticketing, e-learning, e-challan, e-health, e-payment, e-libraries and m-learning etc. Finally, our research 
integrated TAM, EECM and MLA affinity theory to predict the continuance use of MLA in the emerging state, i.e., Pakistan because of their theoretical perspective nature. Upcoming studies with the help of this developed model will help us in the identification of other constructs in e-service quality or e-system quality which might help to improve users' perspective toward continuance use of MLA. Therefore, e-service qualities are of great importance and required in-depth study.

\section{Acknowledgement}

Taif University Researchers Supporting Project number (TURSP - 2020/36), Taif University, Taif, Saudi Arabia

\section{References}

Aharony, N. (2014). Mobile libraries: librarians' and students' perspectives. College \& Research Libraries, 75(2), $202-217$.

Ahmed, A., Zahid, A., Wajid, H., Muhammad, H. R., \& Vighio, S. (2019). Extending UTAUT2 toward acceptance of mobile learning in the context of higher education. Universal Access in the Information Society, 18(3), 659-673. https://doi.org/10.1007/s10209-01900685-8

Ajzen, I. (1991). The theory of planned behavior. Organizational Behavior and Human Decision Processes, 50(2), $179-211$.

Al-faresi, S., \& Patel, N. (2012). The need for an adoption and acceptance framework for mobile digital library services. Journal of Internet Technology and Secured Translations (JITST), 1(1/2), 42-51.

Albashrawi, M., \& Motiwalla, L. (2019). Privacy and personalization in continued usage intention of mobile banking: an integrative perspective. Information Systems Frontiers, 21(5), 1031-1043.

Alfaresi, S. H., \& Hone, K. (2015). The intention to use mobile digital library technology: a focus group study in the United Arab Emirates. International Journal of Mobile Human Computer Interaction, 7(2), $23-42$.

Ali, A., Rafique, H., Arshad, T., Alqarni, M. A., Chauhdary, S. H., \& Bashir, A. K. (2019). A Fractal-Based Authentication Technique Using Sierpinski Triangles in Smart Devices. Sensors, 19(3), 678. https://doi.org/10.3390/s19030678

Ali, A., Shakil, M., Rafique, H., \& Cheema, S. M. (2019). Connection Time Estimation between Nodes in VDTN. International Journal of Advanced Computer Science and Applications, (IJACSA), 10(1), 339-345.

Alzahrani, Ahmed Ibrahim and Mahmud, Imran and Ramayah, Thurasamy and Alfarraj, Osama and Alalwan, N. (2019). Modelling digital library success using the DeLone and McLean information system success model. Journal of Librarianship and Information Science, 51(2), 291-306. https://doi.org/10.1177/0961000617726123

Anderson, J. C., \& Gerbing, D. W. (1988). Structural equation modeling in practice: A review and recommended two-step approach. Psychological Bulletin, 103(3), 411.

Bhattacherjee, A. (2001a). An empirical analysis of the antecedents of electronic commerce service continuance. Decision Support Systems, 32(2), 201-214.

Bhattacherjee, A. (2001b). Understanding information systems continuance: an expectation-confirmation model. MIS Quarterly, 351370 .

Byrne, B. M. (2001). Structural equation modelling with AMOS; Basic concepts applications. Mahwah, NJ: Erlbaum.

Chang, C.-C. (2013a). Exploring the determinants of e-learning systems continuance intention in academic libraries. Library Management, 34(1/2), 40-55.

Chang, C.-C. (2013b). Library mobile applications in university libraries. Library Hi Tech, 31(3), 478-492.

Chen, Y.-H., \& Chengalur-Smith, I. (2015). Factors influencing students' use of a library Web portal: Applying course-integrated information literacy instruction as an intervention. The Internet and Higher Education, 26, 42-55. https://doi.org/10.1016/j.iheduc.2015.04.005

Cheng, Y. (2014). Why do users intend to continue using the digital library? An integrated perspective. Aslib Journal of Information Management, 66(6), 640-662. https://doi.org/10.1108/AJIM-05-2013-0042

Chin, W. W. (1998). The partial least squares approach to structural equation modeling. Modern Methods for Business Research, 295(2), 295-336.

CUI Ranking and Reputation. (2020). Retrieved from https://www.timeshighereducation.com/world-university-rankings/comsatsuniversity-islamabad

Davis, F. (1989). Perceived Usefulness, Perceived Ease of Use, and User Acceptance of Information Technology. MIS Quarterly, 13(3), 319-340. https://doi.org/10.1016/S0305-0483(98)00028-0

Delone, W. H., \& McLean, E. R. (2003). The DeLone and McLean model of information systems success: a ten-year update. Journal of Management Information Systems, 19(4), 9-30.

DeLone, W. H., \& McLean, E. R. (1992). Information systems success: The quest for the dependent variable. Information Systems Research, 3(1), 60-95.

Fishbein, M., \& Ajzen, I. (1977). Belief, attitude, intention, and behavior: An introduction to theory and research, 10(2), $130-132$.

Fu, Y., \& Inskip, C. (2019). Exploring User Experience on Mobile Library Service by Cognitive Mapping. In Proceedings of the 2019 
Conference on Human Information Interaction and Retrieval (pp. 397-400). New York, NY, USA: Association for Computing Machinery. https://doi.org/10.1145/3295750.3298968

Gartner. (2015). Gartner says demand for enterprise mobile apps will outstrip available development capacity five to one. Retrieved from http://www.gartner.com/newsroom/id/3076817

Gartner. (2016). Gartner Mobile App Survey Reveals 24 Percent More Spending on In-App Transactions Than on Upfront App Payments. Retrieved from https://www.gartner.com/en/newsroom/press-releases/2016-05-26-gartner-mobile-app-survey-reveals24-percent-more-spending-on-in-app-transactions-than-on-upfront-app-payments

Hahn, J. (2012). Mobile augmented reality applications for library services. New Library World, 113(9/10), 429-438. https://doi.org/10.1108/03074801211273902

Hair, J. F., Black, W. C., Babin, B. J., \& Anderson, R. E. (2010). Advanced diagnostics for multiple regression: A supplement to multivariate data analysis. Upper Saddle River, NJ: Prentice Hall.

Hairs, J. F., Anderson, R. E., Tatham, R. L., \& Black, W. C. (1998). Multivariate data analysis. Englewood Cliffs, NJ: Printice Hall.

Hsiao, C. H., Chang, J. J., \& Tang, K. Y. (2016). Exploring the influential factors in continuance usage of mobile social Apps: Satisfaction, habit, and customer value perspectives. Telematics and Informatics, 33(2), 342-355. https://doi.org/10.1016/j.tele.2015.08.014

Hsu, C.-L., \& Lin, J. C.-C. (2015). What drives purchase intention for paid mobile apps?--An expectation confirmation model with perceived value. Electronic Commerce Research and Applications, 14(1), 46-57.

Hu, C. P., Hu, Y., \& Yan, W. W. (2014). An empirical study of factors influencing user perception of university digital libraries in China. Library and Information Science Research, 36(3-4), 225-233. https://doi.org/10.1016/j.lisr.2013.10.008

Huh, Y. E., \& Kim, S. H. (2008). Do early adopters upgrade early? Role of post-adoption behavior in the purchase of next-generation products. Journal of Business Research, 61(1), 40-46. https://doi.org/10.1016/j.jbusres.2006.05.007

Hutcheson, G. D., \& Sofroniou, N. (1999). The multivariate social scientist: Introductory statistics using generalized linear models. Sage.

Joo, S., \& Choi, N. (2016). Understanding users' continuance intention to use online library resources based on an extended expectationconfirmation model. The Electronic Library, 34(4), 554-571.

Ju, Y., Park, S., \& Kyoung, E. (2017). Students ' expectation, satisfaction, and continuance intention to use digital textbooks. Computers in Human Behavior, 69, 83-90. https://doi.org/10.1016/j.chb.2016.12.025

Khan, A., \& Qutab, S. (2016). Understanding research students' behavioural intention in the adoption of digital libraries. Library Review, 65(4/5), 295-319. https://doi.org/10.1108/LR-06-2015-0070

Kim, B. (2010). An empirical investigation of mobile data service continuance: Incorporating the theory of planned behavior into the expectation-confirmation model. Expert Systems with Applications, 37(10), 7033-7039. https://doi.org/10.1016/j.eswa.2010.03.015

Lee, J. Y., Paik, W., \& Joo, S. (2012). Information resource selection of undergraduate students in academic search tasks. Information Research: An International Electronic Journal, 17(1), n1. article.

Li, R., Chung, T. L. (Doreen), \& Fiore, A. M. (2017). Factors affecting current users' attitude towards e-auctions in China: An extended TAM study. Journal of Retailing and Consumer Services, 34(August 2016), 19-29. https://doi.org/10.1016/j.jretconser.2016.09.003

Lin, W., \& Wang, C. (2012). Antecedences to continued intentions of adopting e-learning system in blended learning instruction : A contingency framework based on models of information system success and task-technology fit. Computers \& Education, 58(1), 88-99. https://doi.org/10.1016/j.compedu.2011.07.008

Malik, G., \& Rao, A. S. (2019). Extended expectation-confirmation model to predict continued usage of ODR/ride hailing apps: role of perceived value and self-efficacy. Information Technology \& Tourism, 1-22.

Moorthy, K., T, L. C., Ming, K. S., Ping, C. C., Moorthy, K., T, L. C., ... Joe, L. Q. (2019). Behavioral Intention to Adopt Digital Library by the Undergraduates Behavioral Intention to Adopt Digital Library by the Undergraduates. International Information \& Library Review, 51(2), 128-144. https://doi.org/10.1080/10572317.2018.1463049

Nunnally, J. C., \& Bernstein, I. H. (1967). Psychometric theory. McGraw-Hill New York.

Oliver, R. L. (1980). A cognitive model of the antecedents and consequences of satisfaction decisions. Journal of Marketing Research, $17(4), 460-469$

Omotayo, F. O., \& Haliru, A. (2019). Perception of task-technology fi t of digital library among undergraduates in selected universities in Nigeria. The Journal of Academic Librarianship, (November), 102097. https://doi.org/10.1016/j.acalib.2019.102097

Park, N., Roman, R., Lee, S., \& Chung, J. E. (2009). User acceptance of a digital library system in developing countries: An application of the Technology Acceptance Model. International Journal of Information Management, 29(3), 196-209.

Perse, E. M. (1986). Soap opera viewing patterns of college students and cultivation. Journal of Broadcasting \& Electronic Media, 30(2), 175-193. https://doi.org/doi.org/10.1080/08838158609386618

Rafique, H., Anwer, F., Shamim, A., Minaei-Bidgoli, B., Qureshi, M. A., \& Shamshirband, S. (2018). Factors Affecting Acceptance of Mobile Library Applications : Structural Equation Model. Libri, 68(2), 99-112. https://doi.org/doi:10.1515/libri-2017-0041

Rafique, H., Omran, A., Shamim, A., Anwar, F., \& Bashir, A. K. (2020). Investigating the Acceptance of Mobile Library Applications with an Extended Technology Acceptance Model ( TAM ). Computers \& Education, 145(Feburary 2020), 103732. https://doi.org/10.1016/j.compedu.2019.103732

Ruiz Mafé, C., \& Sanz Blas, S. (2006). Explaining Internet dependency: An exploratory study of future purchase intention of Spanish Internet users. Internet Research, 16(4), 380-397.

Sang, S., Lee, J.-D., \& Lee, J. (2010). E-government adoption in Cambodia : a partial least squares approach. Transforming Government: People, Process and Policy, 4(2), 138-157. https://doi.org/10.1108/17506161011047370

Scherer, Ronny and Siddiq, Fazilat and Tondeur, J. (2019). The technology acceptance model (TAM): A meta-analytic structural 
equation modeling approach to explaining teachers' adoption of digital technology in education. Computers \& Education, 128 , 13-35. https://doi.org/10.1016/j.compedu.2018.09.009

Seethamraju, R., Diatha, K. S., \& Garg, S. (2018). Intention to use a mobile-based information technology solution for tuberculosis treatment monitoring--applying a UTAUT model. Information Systems Frontiers, 20(1), 163-181.

Shin, D.-H. (2017). Conceptualizing and measuring quality of experience of the internet of things: Exploring how quality is perceived by users. Information \& Management, 54(8), 998-1011.

Shin, D.-H., \& Shim, Y. (2017). Mapping user experience of multiplatform services: the quality factors in multiplatform television. International Journal of Mobile Communications, 15(5), 554-575.

Straub, Detmar and Boudreau, Marie-Claude and Gefen, D. (2004). Validation guidelines for IS positivist research. The Communications of the Association for Information Systems, 13(1), 63.

Thong, J. Y. L., Hong, S.-J., \& Tam, K. Y. (2006). The effects of post-adoption beliefs on the expectation-confirmation model for information technology continuance. International Journal of Human-Computer Studies, 64(9), 799-810. article.

University Ranking in Pakistan. (2020). Retrieved from http://www.hec.gov.pk/english/universities/pages/rank.aspx

Venkatesh, V., \& Davis, F. D. (2000). A Theoretical Extension of the Technology Acceptance Model : Four Longitudinal. Management Science, 46(2), 186-204.

Xu, C., Peak, D., \& Prybutok, V. (2015). A customer value, satisfaction, and loyalty perspective of mobile application recommendations. Decision Support Systems, 79, 171-183.

$\mathrm{Xu}, \mathrm{F} .$, \& Du, J. T. (2018). Factors influencing users' satisfaction and loyalty to digital libraries in Chinese universities. Computers in Human Behavior, 83, 64-72.

$\mathrm{Xu}, \mathrm{F} .$, \& Du, J. T. (2019). Examining differences and similarities between graduate and undergraduate students' user satisfaction with digital libraries. The Journal of Academic Librarianship, 45(6), 102072.

Ye, Q., Luo, Y., Chen, G., Guo, X., \& Wei, Q. (2019). Users Intention for Continuous Usage of Mobile News Apps : the Roles of Quality , Switching Costs , and Personalization. J SYST SCI SYST ENG, 28(1), 91-109.

Yoon, H. (2016). User Acceptance of Mobile Library Applications in Academic Libraries : An Application of the Technology Acceptance Model. The Journal of Academic Librarianship, 42(6), 687--693. https://doi.org/10.1016/j.acalib.2016.08.003

Zha, X., Xiao, Z., \& Zhang, J. (2014). A survey of user perceptions of digital library e-quality and affinity. Serials Review, 40(1), 3-11.

Zha, X., Zhang, J., Li, L., \& Yang, H. (2016). Exploring the adoption of digital libraries in the mobile context: The effect of psychological factors and mobile context factors. Information Development, 32(4), 1155-1167. https://doi.org/10.1177/0266666915593331

Zha, X., Zhang, J., \& Yan, Y. (2015). Comparing digital libraries in the web and mobile contexts from the perspective of the digital divide. Journal of Librarianship and Information Science, 47(4), 330-340. https://doi.org/10.1177/0961000614532677

Zhang, M., Chen, M., \& Chen, X. (2019). The Influence Factors of User Adoption Intention to University Mobile Library in China -- An Empirical Study Based on the TAM and ISSM. In Proceedings of the 2019 3rd International Conference on Management Engineering, Software Engineering and Service Sciences (pp. 268-272).

Zhang, Z. (2009). Feeling the sense of community in social networking usage. IEEE Transactions on Engineering Management, 57(2), 225-239.

Zhao, Y., Deng, S., \& Zhou, R. (2015). Understanding mobile library apps continuance usage in China: a theoretical framework and empirical study. Libri, 65(3), 161-173.

Zhonggen, Y., \& Xiaozhi, Y. (2019). An extended technology acceptance model of a mobile learning technology. Computer Applications in Engineering Education, 27(3), 721-732. 